\title{
Index for Volume 94
}

AUTHOR AND SUBJECT INDEX. Pages indicating errata are in italic. S indicates June abstract supplement. Publication no. P-2004-1025-01O.

Abad, J. A., S1, S39, S95

Abad, Z. G., S1, S95

Abawi, G. S., S1

Abbas, H. K., S1

Abbasi, P. A., S2

Abdukarimov, A. A., S35

Abi Ghanem, R., S90

Abler, S., S2

Abou Ghanem-Sabanadzovic, N., S2, S90, S91

Abou-Jawdah, Y., S2

Abril, M., S143, S148, S167

Abu-El Samen, F. M., S2, S54, S156

Acevedo, M., S156

Acidovorax avenae

-on watermelon: biocontrol by seed, S30; populations on blossoms, S59

- on watermelon and melon, strain in Israel, S12

Actinidia deliciosa, postharvest rot, biocontrol with grape volatiles, 1280

Adaskaveg, J. E., 52, 163, S3, S25, S31, S49, S83, S97, S149, S151

Adelfinskaya, Y., S113

Adhikari, T. B., 1198, S2

Adkins, S., S3, S4, S48

Adler, N. E., 154

Aebig, J. A., S3

Aegerter, B. J., S3, S149

Aegilops speltoides, leaf rust, new forma specialis, 94

Aerobiology

-Fusarium and Verticillium, dissemination by shore flies, S151

— spore transmission and El Niño events, link, S84

Agarkova, I., S85, S88

Agostini, F., 351

Agostini, J. P., S3

Agrama, H. A., 858

Agrobacterium spp.

-A. tumefaciens, on cranberry stems, galls, cover photo, November

-A. vitis: on grape, wound healing factors, S22; on tobacco and grape, hypersensitivity and necrosis, S39

Agropyron mosaic virus, Hordeum mosaic virus genome sequence, reciprocal monophyly, S32

Ah Fong, A., S48

Ahimera, N., 1189

Ahn, I.-P., S3

Aime, M. C., S82, S124

Ainsworth, T., S23

Akomah, A. R., S101

Alabouvette, C., 661

Albano, J., S113

Albersheim, P., S122

Albiach, M., S131

Albiston, A., S163

Alderman, S., S85

Aldwinckle, H. S., S62

Alexander, B. J. R., S57

Alexander, S. A., S142

Alfalfa

-Aphanomyces euteiches, races in Illinois, S160

-Aphanomyces euteiches and Phytophthora medicaginis interaction, $\mathrm{PCR}$ evaluation, S43

- disease resistance and stand persistence, relation, S5

Alfalfa mosaic virus, on tomato, Am gene, chromosome 6, 345

Alfano, J. R., S121, S136

Alfenas, A. C., S21

Ali, S., 1056, 1061, S3

Alkowni, R., S61

Allan, M. A., S149

Alldredge, J. R., S152
Allelopathy, soilborne pathogens controlled by, S101

Allen, J., S4

Allen, R., S33, S42

Allen, T. W., S3, S4

Allende-Molar, R., S4

Alleyne, A., S156

Allium spp., rusts, biology and sequence analysis, 569

Allorent, D., S92

Almeida, R. P. P., S9

Almond

—bacterial canker, peach hybrid, susceptibility in California, S151

-leaf disease, biocontrol in California, S31

-leaf scorch, factors in California, S36

- union mild etch, scion and irrigation influence, S20

Al-Niemi, T. S., S4

Al-Saadi, A., S26

Alternanthera mosaic virus, on phlox and portulaca, strains, S38

Alternaria spp.: on Arabidopsis thaliana, pathogenicity model study, S42; on carrot, biocontrol with Clonostachys rosea, 551; phylogeny, gene sequences, $\mathrm{S} 42$

-A. alternata, mannitol biosynthetic genes, disruption, S106

-A. brassicicola: on Brassica, pathosystems as model, genomics, S22; on Cakile maritima and C. dentula, in Australia, S9

-A. mali, boscalid sensitivity, assay methods, $\mathrm{S} 63$

-A. porri, on onion, bacterial relation, $\mathrm{S} 156$

-A. solani, azoxystrobin sensitivity, Wisconsin, S161

Alvarez, A. M., S49, S152, S155

Álvarez-Ramos, R., S35

Amane, M., S47

Amanyenu, T., S72

Ambrose, J., S36

Amemiya, Y., 813

American Phytopathological Society

—annual meeting abstracts, S1, 796, 1031

-annual report, 16

—author index to abstracts, S172

-excellence in extension award, 29

- excellence in industry award, 30

-fellows, 20

-international service award, 31

- Lee M. Hutchins award, 28

-Noel T. Keen award, 26

-North Central division, annual meeting abstracts, S156

-Northeastern division, annual meeting abstracts, S163

—officers, representatives, and committees, 14

-Pacific division, annual meeting abstracts, S149

-Potomac division, annual meeting abstracts, S142

—presidential address, Fletcher, 18

-Ruth Allen award, 27

- Southern and Caribbean divisions, annual meeting abstracts, S143

-Southern division, 2004 annual meeting abstracts, S167

—-special session abstracts, S119

- Syngenia award, 32

Ammar, E. D., S4, S134

Amsden, B., S106

Amster, I. J., S121

Amvam Zollo, P. H., S75

Anai, T., 730

Andersen, P. C., S44, S59

Anderson, J. B., S45

Anderson, J. M., 1102, S2, S6, S71
Anderson, K. L., 236

Anderson, L. M., 1228

Anderson, R. C., S4

Andrade, O., 875

Andreu, A., S4, S111

Andrews, D. L., S33

Andrews, J. H., S69

Andrianov, V., S85

Angot, A., S121

Anikster, Y., 94, 505, 569, 632, S125

Annamalai, M., S24

Ansley, J. C., S5

Antibiosis, Pseudomonas syringae, tomato, metabolites for control, S40

Antoun, H., S164

Aoun, M., S8

Aphanomyces cochlioides

-oospores in soil, survival, S90

-on sugar beet, seedling age and susceptibility, $\mathrm{S} 10$

Aphelenchoides spp., PCR-based detection assay, S43

Aphis fabae, Plum pox virus vector, North America, 868

Apiosporina morbosa, genetic structure, Canada, S115

Apoptosis, chile pepper fruit, Colletotrichum gloeosporioides infection, 1295, cover photo, December

Appel, D. N., S5

Apple

-blue mold, control with yeast and sodium bicarbonate, S45

-fire blight: biocontrol with bacteria, iron bioavailability, 1286; potato leafhopper relation, S142; prohexadione-calcium, S76; stigma exudates and relevance, biocontrol, S86; temperature and flower age effect, 901

- fruit decay, chitosan extracts from fungi, role, S91

-postharvest decay: biocontrol plus heat and sodium bicarbonate, S20; Penicillium spp., 44

— proliferation phytoplasma, recovery, 203

—replant orchard soil, seed meal effect, S68

-Rhizoctonia root rot, rapeseed meal amended soil, S20

—scab: biocontrol, application timing, 1305; fungicide resistance, technique, S84; resistance evaluation, technique, S165; resistance gene $V f$, 364; resistance locus genes, 370

- sooty blotch and flyspeck: complex in China and USA, S100; conidial germination, S102; PCR primers in USA, S100; postharvest control, S40; temperature relation, S41

-storage decay, yeast and biocontrol, S67

—white rot, glyoxylate cycle, 970

Arabidopsis spp.: Cochliobolus miyabeanus, novel pathosystem, S81; disease resistance, signaling pathway, S56; oomycete and bacterial pathogens, abscisic acid, S72; response to Alternaria and Pseudomonas, profiling, S122; RPS4 gene, characterization, S115; Turnip mosaic virus, RNA silencing and broadspectrum resistance, 730

-A. thaliana: resistance, bacterial diseases, S135; Rhizoctonia solani, no wilt, 289

Aragaki, M., 561, S155

Araujo, W. L., S56

Arauz, L. F., S52

Arboleya, J., S156

Archibald, D. D., S55, S117

Archipiano, M., 578

Ariss, J. J., S5

Armentrout, D. K., S28

Armillaria spp.: genetic diversity in South 
Carolina, S93; saprophytic and parasitic, interaction, S22; tree mortality and annual burning effect, $\mathrm{S} 45$

-A. ostoyae: phylogeography, western USA, S38; on Pinus pinaster, primary and secondary infection, dynamics, 125

Arterburn, M., 932

Arvidson, D. N., S59

Ascochyta spp.: on legumes, host specificity, S41

-A. rabiei: on chickpea, debris fungus competition, S27; on chickpea, scion and rootstock relation, $\mathrm{S} 17$; migration pattern and gene flow, S127

Asenstorfer, R. E., 1207

Ash (see also Fraxinus sp.)

—branch dieback, California, S149

Ash, G. J., S163

Ash, J. S., S93

Asher, M. J. C., 209

Asparagus

-Fusarium spp., cultural practices and plant age, S166

-Fusarium oxysporum and sodium chloride, replanted fields, $\mathrm{S} 164$

Aspergillus spp., RNA interference pathway, analysis, S38

-A. caelatus, synnema and sclerotium production, substrate effect, S68

-A. flavus: on corn ears, aflatoxin and inbred analysis, 1107; on corn kernels, biocontrol, $\mathrm{S} 23$; genome sequencing, S122; on maize, chitinase, growth inhibition, 82; on pistachio and fig, atoxigenic strain in California, S26; in soil, spatial patterns in Texas, S45; vegetative compatibility groups, variability, S21; VERB synthase, MAFA, interaction, S28

-A. niger, on onion, green protein, S94

Assa, B., S61

Assis Filho, F. M. de, 333, S5

Atallah, Z. K., 737

Aureobasidium pullulans, on apple, rainfall effect, S69

Autio, W. R., S142

Aveling, T. A. S., S55

Avelino, J., S92

Avena sterilis (see also Oat)

- crown rust, virulence pattern in USA and Israel, 505

Avila-Adame, C., S5

Avilés, M., 1094

Avocado, Phytophthora cinnamomi, microbial suppression in soil, S68

Ayllon, M., S131

Azad, H., S152

Azalea, Rhizoctonia web blight, plant spacing effect, S21

Azam, M. A., 296

Azevedo, J. L., S56

Babadoost, M., S5, S44

Babin, M., 69

Bacillus, biocontrol symposium:

-formulation, 1267; integrated pest management role, 1272; nature and application, 1244; Paenibacillus spp. relation, ecology in agricultural systems, 1252; spore coat, 1249; systemic resistance and plant growth promotion, 1249; taxonomy, 1245

-B. subtilis: Pythium damping-off on sugar beet suppressed by, temperature, 351; Rhizobium inoculant interaction, dry bean and soybean root rot, $\mathrm{S} 144$

Backus, E. A., S6

Bacon, C. W., 796

Bacteria

- Gram-positive, Type III secretion, S123

-multiplex detection, flow cytometry, S105

-plant-associated, phylogenetic and genomic perspective, $\mathrm{S} 83$

Bactericides, copper, peach and nectarine phyto- toxicity, S56

Bacteriophage, holin and endolysin, genes, Ralstonia and Xanthomonas control, S87

Bae, H., S6

Bae, J. J., S14

Bae, K. S., S81, S114

Bai, X., S123

Bailey, B., S6, S51

Bailey, D. J., 535

Baker, C. A., S24

Baker, C. J., S88

Bakker, P. A. H. M., S108

Balaji, B., S2, S6

Baldauf, P. M., S163

Balesdent, M. H., 578

Baliji, S., 772, S6

Balogh, B., S6

Bancal, M.-O., 712

Bandele, O., S20

Bandla, M. D., S1, S39

Bandurska, K., S55

Banke, S., S126

Banko, T. J., S6

Bao, Z.-L., 1048

Barak, J., S128

Baranwal, V. K., S35

Barbetti, M. J., S60

Barbosa Neto, J. F., S23

Bar-Joseph, M., S131

Barker, R., S23

Barley

- crown rust, resistance gene Rpc1, molecular mapping, 858

-Fusarium head blight, deoxynivalenol accumulation: genetic effect, 766; and resistance, 1145

-leaf spot, physiological, oxidative stress, 584

-net blotch, mapping resistance gene, S32

- powdery mildew, chitinase transcripts, $\mathrm{R}$ gene resistances, $\mathrm{S} 114$

- Septoria speckled leaf blotch, resistance gene markers, S58

Barley yellow dwarf virus

- Cereal yellow dwarf virus comparison, phylogenic analysis, Alaska, S88

- sequencing project, with Cereal yellow dwarf virus, $\mathrm{S} 71$

- on winter wheat, bird cherry-oat aphids, S170

Barnes, C. W., S6

Barney, W. P., S103

Baron, J. J., S17

Barreto, D., S83

Barros, S., S61

Barta, A., S84

Bashir, N. S., 722

Bassett, C. L., S46

Bastien, C., 1358

Bates, G., S7, S147

Batuman, O., S131

Batzer, J. C., S40, S41, S100, S102

Baum, T., S25, S33, S42, S82, S100

Baumann, K., S11

Baumgartner, K., S7

Bayon, C., S126

Bean (see also Phaseolus vulgaris)

- anthracnose, new race, $\mathrm{S} 25$

-damping-off, etiology in Iran, S92

—root health, soil bioassay, S1

Bean dwarf mosaic virus, recombinant viruses and viral proteins, $\mathrm{S} 117$

Bean pod mottle virus

-on soybean: foliar insecticide timing, S117; insect resistance, S84; vector for gene expression, S114

-soybean line reaction, yield, S19

Beattie, G. A., S17, S91

Beaulieu, C., S26

Beauveria bassiana, on millet seed, biopesticide, S98

Becker, C. M., S140

Becker, J. O., S7, S78, S129, S149
Beckett, R., S71

Beede, R., 388

Beeson, J., S48

Beet curly top virus

-on bean, Bct gene for resistance, mapping sequence, 320

- capsid protein, domain mapping, leafhopper transmission, S134

-in snap bean, SCAR marker, S153

-weed and crop hosts in California, S111

-in weeds, New Mexico, S22

Beet necrotic yellow vein virus

- detection in soil, S168

- on sugar beet: control strategies in UK, 209; PCR to quantify resistance, S168; resistancebreaking isolates, California, S62

Beet soilborne mosaic virus, genetic variability, S170

Beever, R. E., 1129

Begomoviruses, species number, S124

Behle, R. W., 1267

Bélanger, R. R., 177, S146, S165

Bell, A., S69

Bellizzi, M., S135

Bellows, C., S65

Belton, M. P., S89

Bemisia tabaci

-begomoviral capsid determinants, S134

- Cotton leaf crumple virus vector, evolutionary relations, 1068

Ben Yehuda, P., 94, 632

Ben-Daniel, B. H., 1042

Bender, C. L., S27, S97, S108, S121, S124, S152, S169

Benhamou, N., 177, 693, S146

Bennett, R. S., S7

Benson, D. M., 780, S7, S167

Benson, E., S12

Bent, A. F., S133

Bentley, A. R., S7

Bentley, T. C., S4

Benyvirus, real-time PCR use, S67

Bergdahl, D. R., S163

Berger, P., S138

Bergervoet, J. H. W., 463, S105

Bergot, M., 826

Bergstrom, G. C., 527, S7, S93, S163

Berland, P. A., S8

Bermudagrass (see also Cynodon spp.)

- spring dead spot, control strategies, fungicides, S167

— sting nematode, management practice, S170

Berney, M., S129

Bernier, C. C., 236

Bernier, L., 1323, S8, S29

Berruyer, R., S136

Berry, D., S109

Berry, S. A., S84

Bertrand, P. F., S99

Best, V. M., 1172, S41

Bever, J., S119

Bewick, T. A., S137

Bextine, B., S8

Bhagwat, A., S128

Bigelow, D. M., S54, S154

Billings, R. F., S13

Biocide, chlorine dioxide gas, applications, S150

Biofilm

- bacterial and fungal, biocide evaluation, S78

—-salmonella and plant organisms, S128

Biological control

- agents and amendments on soil microbes, S56

—apple fire blight, antagonists, factors, 901

-Bacillus: potential, S74; for Sclerotinia sclerotiorum on canola, zwittermicin A, S116

-Bacillus symposium: formulation, 1267; integrated pest management role, 1272; nature and application, 1244; spore coat, 1249; Paenibacillus spp. relation, ecology in agricultural systems, 1252; systemic resistance and plant 
growth promotion, 1259; taxonomy, endospore formers, 1245

-B. subtilis: Pythium damping-off on sugar beet suppressed by, temperature, 351; Rhizobium inoculant interaction, dry bean and soybean root rot, $\mathrm{S} 144$

-B. licheniformis for turfgrass diseases, S109

-Clonostachys rosea for Alternaria spp. on carrot, 551

- compost tea for damping-off, Pythium ultimum, 1156

- endophyte for Verticillium yellows on Chinese cabbage, 412

—foliar diseases, modelling, S112

-Fusarium wilt of chickpea, management factors, 946

- grape plant volatiles: for Botrytis cinerea, 924; on kiwifruit, 1280

- Microsphaeropsis ochracea on Venturia inaequalis, 1305

- mitovirus $3 \mathrm{a}$ in Sclerotinia homoeocarpa hypovirulent isolates, 917

-nature and application of Bacillus spp., symposium, 1244

—nematodes by Paecilomyces lilacinus, S51

- oxygen competition, mechanism, S41

-Phytophthora crown rot on squash, watermelon stem blight, S94

- Phytophthora parasitica by composted swine waste, 780

—pseudomonads phlD+, Ohio, S69

- Pseudomonas fluorescens for fire blight, iron bioavailability, 1286

-Puccinia psidii and Oxyops vitiosa for Melaleuca quinquenervia, in Florida, S87

-Trichoderma, products, mechanisms and use, S138

-Trichoderma hamatum, systemic resistance induced by, factors, S138

-Trichoderma harzianum: for Colletotrichum graminicola and Pythium ultimum, on maize, 147; proliferation in soil, image analysis and protein use, 1383

-Trichoderma spp., biofungicide, molecular biology of interaction, $\mathrm{S} 139$

-Trichoderma virens: defense response elicitor, 171; mechanisms, S138

-yeast, Botrytis cinerea on geranium, phylloplane, 196

Biological waste, amendments, compost, health benefits, $\mathrm{S} 127$

Bird, G., S129

Birren, B., S122

Bisaro, D. M., S150

Bishop, B., S161

Bishop, J., S24

Biswas, K. K., S8

Black, M. C., 772, S6

Blackwell, L., S63

Blanco, F., S48

Block, C. C., S8, S34

Blodgett, A., S91

Blodgett, J. T., S8

Blomquist, C., 621

Bloomberg, J., S31, S146

Blouin Bankhead, S., S8

Blueberry

-Alternaria fruit rot, postharvest control with fungicides, $\mathrm{S} 10$

- anthracnose, bud infection and fruit rot, S25

- Bacillus subtilis as flower application, risk, S75

-Botryosphaeria stem blight, susceptibility, S147

- fruit drop, virus association, S66

- fruit surface microflora, biocontrol agents, S91

- Septoria leaf spot, survival analysis, S77

Blueberry scorch virus, detection and analysis, S84

Blumer, S. E., S116

Blumeriella jaapii, on cherry, fungicide sensitivity, Michigan, S86
Blunt, T. D., S8

Boal, R. J., S112

Bobrova, V. K., S67

Bock, C. H., S9, S81

Bockus, W. W., S48

Bodaghi, S., 1337

Bodman, S. V., S103

Boehm, M. J., S93, S102, S115, S159

Boger, C., S144, S147

Bok, J. W., S38

Boland, G. J., 917

Bolda, M., S104

Bolduc, T., S9, S66

Bolger, K. A., S45

Bonacic, I., S44

Bonants, P. J. M., 613

Bond, J. P., S158

Bonello, P., S102, S133

Boore, J. L., S85

Borneman, J., S78, S129

Boronin, A., S67

Borrero, C., 1094

Borth, W. B., S9, S149, S154

Bos, J. I. B., S156

Bossolini, E., 1036

Bostock, R. M., S58, S109, S141

Boston, R. S., 82

Botella, F., 470

Botryosphaeria spp., sporulation, temperature effect, S143

-B. dothidea, on apple, glyoxylate cycle, latent infection, 970; conidial dispersal, drop impactions and rain, 1189; on pistachio fruit, temperature and maturity effects, S70; on pistachio, panicle and shoot blight in California, S70;on pistachio, population structure, California, 326

Botryotinia fuckeliana, osmosensing histidine kinase, fungicide response, 1129

Botrytis cinered

-on geranium, fungicides and phylloplane yeasts, control, 196

-on grape: flower infection, 850; plant volatiles as biocontrol agents, 924

-on lisianthus: airflow system, S103; fungicides, $\mathrm{S} 108$

Botta, G., S44

Bottner, K. D., S58

Boucher, C., S121

Bounds, R. S., S156

Bourett, T., S42

Bouvet, G., S8

Bovitz, J. J., S93

Bowden, R. L., 520, 961, 1013, S58

Bowen, K. L., S9, S13

Bowers, T. A., S9

Bowles, M. L., S45

Boyce, A., S74

Boza, E. J., S9

Brachycaudus persicae, Plum pox virus, North America, 868

Bradeen, J. M., S71, S91

Brading, P. A., 497

Bradley, C. A., S10, S51, S157

Bradshaw, J., S10

Braga, M. R., S59

Brandl, M., S128

Brannen, P. M., S10

Brantner, J. R., S10

Brassica spp.

- B. campestris, Verticillium yellows, endophyte for control, 412

-B. napus: major specific resistance genes, 578; Sclerotinia stem rot resistance, mapping, S12

Bredehoeft, M. W., S98

Breeden, J., S2

Bremia lactucae, on lettuce, sporulation factors, 396

Brenneman, T. B., S50, S99, S145, S147, S167, S170

Breuil, C., 1323, S8
Brewer, M. T., S163

Briggs, M., S135

Bright, D. E., S163

Bristow, P. R., S10, S150

Brlansky, R. H., 978, S10, S37, S90

Broad bean mottle virus, temperature and host effect, defective RNAs, 69

Brock, J. H., S146

Brodbeck, B., S59

Broders, K., S10

Bronson, J. J., S11

Broome, J. C., S11, S136

Brown, A., S8

Brown, D. (N.C.), S122

Brown, D. W. (Ill.), S68, S120

Brown, G. R., S133

Brown, J. K. M. (UK), 497

Brown, J. K. (Ariz.), 1068, S11, S43, S124, S134, S 150

Brown, L. G., S11, S138

Brown, R. L., 938, S11, S18

Brown, S. E., S123

Browne, G. T., S11

Bruck, R. I., S9

Bruckart, W. L., III, S12, S142

Brule-Babel, A. L., S22

Brun, H., 578

Bruton, B., S170

Bryer, J., S11

Bryson, K. K., S93

Bucher, E. S., S12

Buchwaldt, L., 236, S12

Buck, J. W., 196, S3, S4, S73, S111, S145

Buckley, K., S150

Buell, C. R., S121

Bujarski, J. J., 69

Bull, C. T., S12, S83, S150

Burch, K. B., S9

Burdman, S., S12, S135

Burdon, J. J., S9, S126

Burger, A., S123

Burgess, L. W., S7, S61, S84

Burns, J. K., S25, S56

Burpee, L., S3, S4, S82, S146

Burr, J. A., S110

Burr, T. J., S22, S39, 1031

Burrell, D., S145

Burrows, M., S12

Busboom, K. N., 1107

Bush, B. J., 88

Bushnell, W. R., 569

Buss, G. R., 687

Busto, J. L., 1031

Butchko, R. A. E., S120

Butler, E. L., S167

Buyer, J. S., S88

Byrne, J. M., S13

Caballero, R., S150

Cadle-Davidson, L., 527, S33, S163

Cadle-Davidson, M., S163

Caesar, A. J., S57

Caesar-TonThat, T. C., S57

Cahill, D. M., S72

Cai, G., S13

Cai, S. S., S29

Calabro, J. M., S13

Caldiz, D., S4

Calenge, F., 370

Caladium, Fusarium, fungicide combinations, S169

Callahan, S. D., S13

Calla lily, soil fumigants, drip application, S34

Calvert, L., S135

Camacho-Casas, M. A., S30

Camberato, J. J., S66, S81, S83

Cameron, K. D., S48

Camilli, K. S., S13

Camp, M. J., S20

Campbell, H. L., S13

Campbell, M. A., 302 
Campbell, W. L., S58

Canaday, C. H., S167

Canola

—blackleg, strain diversity, in Canada, S18

- Sclerotinia stem rot, foliar fungicides, S10

Cantaloupe (see also Cucumus melo and Melon)

- polygalacturonase-inhibiting protein activity, origin, S168

Canteros, B. I., S6

Cantonwine, E. G., S13, S143, S168

Cao, Y. L., 402

Caolo-Tanski, J. M., S150

Caparon, M., S123

Capsicum annuum (see also Pepper)

- anthracnose, programmed cell death and resistance, 1295

-fruit rot, new in Canada, S155

—rhizosphere bacteria, quantifying, S98

-root-knot nematode, pepper-cucumber rotation, resistance and sodium, $\mathrm{S} 102$

Caranta, C., 345

Carballo, A., S72

Carbone, I., S35

Cardona, C., S50

Cardwell, K., S129

Career in plant pathology

-basic research in chemical company and university, S141

- chemical company and private practice, S140

- extension, S141

— job-hunting, international student, S141

- job satisfaction, S141

-multinational fruit company, agricultura chemicals, S141

_ perspective on opportunities, S141

- sales and distributor account management, S141

- science and practice, S140

-USDA research and regulation, $\mathrm{S} 141$

Carisse, O., 1305

Carlson, K. M., S14

Carlson, R. W., S49

Carpenter, J., S91

Carriquiry, A. L., 102, 1027

Carris, L., S88, S108

Carroll, G., S83

Carroll, R. B., S24

Carrot

- Alternaria and Cercospora foliar blight, disease management, S161

-Alternaria spp., biocontrol with Clonostachys rosea, 551

-bacterial blight, Pacific Northwest, S26

-blight, inoculum source and population genetics, S70

- foliar blight, scouting and Tom-Cast program, S156

- foliar diseases, IPM strategy in Wisconsin, S88

- foliar pathogens, weather-based fungicide program, S89

-rot, fungi in Mexico, S144

Carson, M. L., 88, 862, 892, S125

Carter, M. L., S64, S69

Cartinhour, S., S121

Cartwright, R. D., S1, S9, S92, S107

Casadevall, A., S132

Cassava, bacterial blight, resistance and quantitative trait loci, in Africa, 1084

Castañeda, A., S14

Castilla, N., 672

Castro, A., S156

Catharanthus roseus

-Phytophthora disease, inoculum application pressure, S6

- Rhizoctonia root rot, fungicides, S145

Cauliflower mosaic virus, on Nicotiana spp. hypersensitivity, S14

Cavaletto, J. R., 1198

Cawly, J. D., S14

Cecarelli, R., S164

Cell death, on tobacco and tomato, nonhos pathogen induced, S49

Celoy, R., S14, S109

Center, T. D., S87

Cepeda-S, M., S143

Ceratocystis spp.

-C. albofundus, wilt on South African trees, S89

-C. fibriata: on clove, decline in North Sulawesi, S61; on Ficus and Colocasia, in Asia and Polynesia, S160

-C. resinifera, on conifers, genetic variability and structure, Canada, 1323

Ceratopteris richardii, on fern, culture and maintenance, S105

Cercospora spp.: cercosporin, genes involved, S41; on corn, sorghum, and smooth brome, S10

$-C$. arachidicola, on peanut, strip-tillage effect, analysis, $\mathrm{S} 13$

-C. beticola, on sugar beet, benzimidazole sensitivity, S24

-C. kikuchii, on soybean, populations, S13

-C. sorghi, on sorghum, other Cercospora sp. relations, 743

Cereal yellow dwarf virus, on Thiopyrum intermedium, resistance basis, 1102

Ceri, H., S9, S66, S78

Cespedes Leon, M. C., S125

Cha, J.-S., S19

Chacón, M. G., 154

Chakraborty, N., S14

Chakraborty, S., 221

Challberg, H., S74

Chamberlain, H. L., S14

Chambers, D., S103

Champouret, N., S136

Chan, H. T., Jr., S153

Chan, Y.-K., S15

Chang, C. J., S15

Chang, S. P., S15

Chang, S. W., S15

Chang, T. H., S15

Chang, W.-S., S15

Charkowski, A. O., S113, S162

Charron, C. S., S91

Chartrain, L., 497

Chase, T. E., S114

Chastagner, G. A., S16, S24, S150

Chatchawankanpanich, O., S19

Chatterjee, A., S16, S40, S121

Che, X., S131

Checkai, R. T., S96

Chellemi, D. O., S16

Chen, C., S16, S17

Chen, D. (Canada), 302

Chen, D. Y. (Taiwan), S76

Chen, H. (N.J.), S17, S103, S150

Chen, H. R. (China), S43

Chen, H. Y. (China), S29

Chen, J. (Calif.), S17, S36

Chen, J. (Fla), S77

Chen, J. (N.Y.), 147

Chen, L., S17, S134

Chen, P. (Va.), 687

Chen, P. (Ark.), S7, S45, S116

Chen, R. S., S17, S76

Chen, W., S17, S18, S27, S47, S132

Chen, X. M., 737, S18, S80

Chen, Y., S18

Chen, Z.-Y., 938, S11, S18

Chenault, K. D., S18, S92

Cheng, M., S18, S151

Cheng, Y. H., S76

Chérif, M., S87

Cherry

-rusty mottle disease, new virus association, S89

- viruses, new in northern California, S91

Chickpea (see also Cicer arietinum)

-Ascochyta rabiei, melanin production and pathogenicity, S18

Chile pepper, Verticillium wilt and Phytophthora root rot, Brassica crop residue effect, S63
Chilvers, M. I., S18

Chipps, T. J., S19

Chiroleu, F., 138

Chisholm, S., S135

Chiu, L-R., 1031

Cho, J. D., 111

Cho, K. Y., S59

Choi, G. J., S59

Choi, J. J., 651, S19, S64, S69

Choi, S. H., S52

Chomdej, O., S19

Choo, T. M., 1145

Choquette, C. J., S60

Choueiri, E., S90

Chuma, I., 454

Chun, W., S85

Chung, E. J., S59

Chung, J.-E., S19

Chung, K. R., S41, S56, S105

Chung, Y. R., S59

Chunwongse, J., S19

Church, G. T., S19

Cicer arietinum (see also Chickpea)

-Fusarium oxysporum, race evolution, fingerprinting, 228

-Fusarium wilt, integrated management and biocontrol, factors, 946

Cicero, J. M., S134

Cihlar, C. L., S157

Cihlar-Strunk, C. L., S19

Ciomperlik, M. A., 1136

Cipriani, M. G., 484

Citrus

-bacterial diseases, systemic resistance, induction, S25

-black spot, fungicides, storage temperature, postharvest symptoms, S3

—budwood certification program, Texas, S145

- canker: bacteriophage association, S6; diagnosis, sampling methods, 61; dispersal and wind speed effect, S9; eradication program in Florida, status, S14; image analysis, S81

- greasy spot, mating and pseudothecial development, 978

— green mold, curing, Florida, S115

- greening bacterium, PCR detection, sodium sulfite in DNA extraction, S35

-Penicillium digitatum, fludioxonil sensitivity, S78

-postharvest decay, Penicillium spp., acidification, 44

— psorosis, natural spread, S80

-resistance genes and salicylic acid pathway, S29

- tristeza: spatial pattern in Mexico, S35; worldwide perspective, $\mathrm{S} 130$

Cirus leprosis virus, molecular characterization, S36

Citrus tristeza virus

-aphid transmission, population dynamics, S8

_ brown citrus aphid relation, field spread, S86

- California isolates, transmissibility, S131

-defective RNAs, biology, S131

-epidemiology, S131

- gene silencing, in tobacco, S90

- genetic analysis, gene deletion effect on host range, $\mathrm{S} 92$

-GFP-tagging, S30

-on mandarin, optical density readings, S85

- model and tool, host and transmission, S131

-pathosystem evolution, S131

- populations and aphid transmission, S90

—resistance gene, positional cloning, S132

-RNA silencing, suppressors, S131

—-stem pitting, mapping, S30

- stem pitting and mixed virus infection, S10

Civerolo, E. L., 1136, S17, S31, S36, S61

Clark, C. A., S19, S54, S105

Clark, T. A., S114

Clarke, B. B., S164 
Clarkson, J. P., 268

Clavibacter michiganensis

- genome, S123

_-genome sequencing, S123

-on tomato: immunoassay on seeds, S152; risk analysis strategy, S49

-on tomato and potato, genetic diversity, Russia, S43

- tomato proteome interaction, S123

-virulent and nonvirulent forms, differentiation, S155

Claviceps africana, conidia, viability factors, S146

Clements, M. J., 251, S120

Cleveland, T. E., 938, S11, S18

Climate, China, disease changes from 1952 to 2002, S60

Clitoria ternatea, protein, antimicrobial and insecticidal properties, S50

Clonostachys rosea, biocontol of Alternaria spp., on carrot, 551

Clover yellow vein virus, on snap bean, identification, S57

Cluck, D. R., S79

Coaker, G., S123, S135

Cobb, A. C., S26

Cobb, W. T., S124

Cochliobolus spp.

-C. heterostrophus, on maize, race $\mathrm{O}$, resistance mapping, 862

-C. miyabeanus, on rice, Magnaporthe grisea comparison, $\mathrm{S} 3$

Cocoa, pod rot, biopesticides, biocontrol, S28

Coetzee, M. P. A., S119

Coffee, leaf rust, biocontrol with 17 antagonists, S37

Cogal, A. G., S87

Cohen, M. F., S20, S68, S125

Cohen, O., S131

Cohen, Y., 1042

Coir, extracts, Phytophthora and Botrytis affected by, S43

Colburn, G. C., S25

Cole, A. B., S14, S20

Cole, F. M., 850

Collar, C., S31

Colletotrichum sp., pepper, isolate comparison using Biolog, S142

$-C$. acutatum: on almond, temperature-wetness relation, $\mathrm{S} 25$; on citrus, jasmonic acid and salicylic acid induction, S56; on highbush cranberry, overwintering, S142; on strawberry, anthracnose, pyraclostrobin, S166; on strawberry, strobilurin fungicides, S94

-C. gloeosporioides: on chili pepper, resistance and programmed cell death, 1295; on strawberry, genetic analyses, other hosts, 446; on strawberry, other hosts, S64; on Stylosanthes scabra, canopy size and severity at high $\mathrm{CO}_{2}$, 221

-C. graminicola: evolutionary history, Bayesian analysis, S164; on maize, Trichoderma harzianum seed treatment, 147; on putting greens, nitrogen, growth regulators, and herbicide effect, S164

-C. orbiculare, on cucumber, resistance and systemic fungicide, applications, S42

$-C$. trifolii, on alfalfa, antioxidant and programmed cell death, S16

-C. truncatum, on lentil, races and resistant germ plasm, 236

Collins, D. J., S20

Collmer, A., S16, S20, S40, S121

Collmer, C. W., S20

Colocasia esculenta, agricultural practices, Hawaii, S104

Colyer, P. D., S89

Comis, A., 147

Compartmentalization, Dutch elm disease and Scleroderris canker, anatomy and chemistry, S133
Compost

-Pythium ultimum suppressed by, 1156

-rhizosphere and phyllosphere agriculture, S137

- swine waste, Phytophthora parasitica in

horticultural medium, 780

Conifers, host-pathogen interraction, anatomy and chemistry, S133

Conn, K. L., S2

Connell, J. H., S20

Connor, K. F., S110

Constantin, R. J., S169

Conway, W. S., 44, S20, S46, S91

Cooksey, D. A., S41, S95, S152

Cools, H. J., S20

Cooperative State Research, Education, and Extension Service, agricultural pathogen role, new and emerging, S129

Copes, W. E., S21, S143

Coppinger, P., S135

Corbin, K. C., S59

Cordova, L., S72

Corn (see also Maize)

-aflatoxin and fumonisin production, heat stress effect, $\mathrm{S} 1$

-aflatoxin production, kernel water relations, S11

-Aspergillus ear rot and aflatoxin production, resistance inheritance, inbreds, 1107

-Cercospora zeae-maydis, inoculation method, S30

-flea beetle, Stewart's disease relation, quantification, S160

-Fusarium ear and kernel rot, fumonisin, resistance sources, 251

-Fusarium ear rot, resistance and fumonisin, S54

-leafhopper and stunt, insecticide evaluation, S31

—Stewart's disease, planting date effect, S160

Cornus florida (see also Dogwood)

- powdery mildew: biocontrol, S72; fungicides, S37

Correa, V., S123

Correll, J., 296, S4, S9, S34, S44, S47, S111

Cortesi, P., 544

Cortinas, M. N., S21

Corynespora cassiicola, host range, Guam, S97

Costa, H. S., S152

Costanzo, S., S21, S70

Cota, L. V., S21

Cother, E. J., S163

Cotton

— seedling disease, environmental factors, S89

-Thielaviopsis basicola, nematode and soil temperature relation, $\mathrm{S} 72$

Cotton leaf crumple virus

$-D N A-A$ and DNA-B components, seedling infection, cover photo, October

-evolutionary relations, recombination and reassortment, 1068

Cotty, P. J., S21, S26, S45

Coulibaly, M., S48

Counce, P. A., 819, S58, S96

Courty, P. E., S133

Coutinho, T. A., S74

Cover photo

— barley, rusts, substomatal vesicles, January

- chili peppers, resistance response to Colletotrichum gloeosporioides, December

- citrus, Penicillium digitatum, wounded fruits, July

-Cotton leaf crumple virus, DNA-A and DNA-B components, October

— cranberry, stem galls, November

-model, epidemiological, nested structure, August

- Mycosphaerella citri, pseudothecia, September

-Puccinia allii, teliospore germination, June

-Puccinia graminis, on ryegrass, secondary spread, March

—rice, Magnaporthe, blast symptoms influenced by silicon, February

-Verticillium dahliae, on pistachio, stem infection, April

-Verticillium longisporum, on Chinese cabbage, endophyte on seedlings, May

Covert, S. F., S133

Cowger, C., S21

Cowling, S. G., S22

Cox, C. M., 961

Cox, K. D., S22

Cox-Foster, D., S134

Coyne, D. P., S73

Cramer, R. A., 184, S22, S42

Cranberry

— bacteria localized in galls, anatomy, 1172

- Lophodermium twig blight and fruit rot, fungicides, S150

- stem gall: cover photo, November; indoleacetic acid association, 1164

Crane, C. F., S2

Craven, K. D., S22

Creamer, R., S22, S69

Creasap, J. E., S22

Creswell, T. C., S95

Cromer, E. E., S22

Cronartium ribicola, on white pine, gene distribution, western North America, 751

Crouch, J., S164

Crous, P. W., S21

Crow, F., S125

Crowe, F. J., S26

Crowley, M., S68

Crowley, T. M., S23

Cryphonectria cubensis, canker in trees in Africa, S74

Cryptococcus nodaensis

-freeze-drying tolerance, melezitose effect, S106

- survival, cold shock, S115

Csinos, A. S., S67, S144, S146, S157

Cubero, J., S25

Cubeta, M. A., 88

Cucumber

-abamectin seed coating, root-knot nematodes, S149

-resistance to anthracnose and angular leaf spot, systemic, S117

-root-knot nematode, nematicide comparisons, S7

Cucumber mosaic cucumovirus, on gladiolus, biolistic inoculation, S3

Cucumber mosaic virus

— foreign genes, chemical regulation, S100

—on melon and weeds, Spain, 992

- mutation and recombination, 912

- on tomato, jasmonic acid and ethylene, S112

Cucumis melo (see also Cantaloupe and Melon)

-polygalacturonase-inhibiting protein in fruit, cDNA sequence, 337

Cucurbit leaf crumple virus, on cucurbit, in California, S37

Cucurbit yellow stunting disorder virus, detection, recombinant coat protein, $\mathrm{S} 2$

Cui, W., 1129

Cui, Y., S16, S40

Culbreath, A. K., S13, S50, S143, S145, S168

Culture, agar, storage temperature, desiccation, S114

Cumagun, C. J. R., 520

Cummings, T., S76

Cunnac, S., S121

Cuppels, D. A., S23

Curley, J., S14, S23

Curry, E. A., 901

Curry, K. J., S143, S148, S167

Curtis, V. L., S82

Curtovirus sp., Spinach curly top virus, new in Texas, 772

Cuzick, A., S107

Cyclaneusma minus, molecular characterization, $\mathrm{S} 23$ 
Cylindrocarpon destructans, on ginseng, detection with molecular techniques, S45

Cynodon transvaalensis (see also Bermudagrass)

-bluegrass overseeding, golf course greens, fungicides, S81

da Graça, J. V., S80, S145

Dahleen, L., 858

Dahlia mosaic virus, on dahlia, survey in USA, S81

d'A. Hughes, J., S101

Dalby, M., S136

Daleo, G., S64, S111

Dalhbeck, D., S135

Dallot, S., 1390, S23

Dally, E. L., S123

Dal Soglio, F. K., S23

Damann, K. E., 938, S18, S23

Damasceno, C. M. B., S24

Damicone, J. P., S168

Damour, L., S60

Damsteegt, V. D., 868, S10, S24, S93

Dandekar, A. M., S90, S100

Dangott, L. J., S26

D’Arcy, C., S139

Dardick, C., S135

da Rocha, A., S156, S157, S161

Dart, N. L., S24

Darvill, A. G., S122

D'Ascenzo, M. D., S20

Datnoff, L. E., 177, S88, S146

Daub, M. E., S41, S102, S106

Daughtrey, M., S164

Davey, J. F., S24

Davidson, R. M., S24

Davis, A. R., 337

Davis, E., S25, S33, S42, S43, S82, S100

Davis, J. M., S133

Davis, R. E., S116, S123

Davis, R. F., S102

Davis, R. M., S70

Davis, S. B., S38

Davis, T., S96

Davison, D. A., S24

Dawson, W., S30, S92, S131

Day, B., S135

Dean, R. A., S26, S46, S122, S135, 1032

Deboer, G., S113

De Boer, S. H., S66

De Carli, M. L., S23

Deenick, J., S104

Dekkers, M. G. H., S25

de la Bastide, P., S8

de la Fuente, L., S24, S67

de los Reyes, B., S44

Delourme, R., 578

Delphinium spp., powdery mildew, fungicides and factors, $\mathrm{S} 108$

del Rio, L., S25, S39, S157, S160

DeLucca, A., S148

DeMarsay, A., S25, S142

Dendy, S. P., 961

Deng, C. L., S29

Deng, F., 917

Deng, J., 1032

Denis, G., S140

Denny, T. P., S49, S62, S121

Deom, C. M., 333, S5, S74

Derie, M. L., S26, S85

Derobertis, C., S23

DeRose, E., 759

Desjardins, A. E., S120

Deslandes, L., 289

de Souza, J. T., S25

Desprez-Loustau, M.-L., 826

Devall, M. S., S110

De Vos, O., S94

De Wolf, E. D., S72, S164

Dhulipala, M., S25

Diab, H. G., 780, S25, S82
Diagnosis

-PCR capabilities, University of Kentucky, S106

- tree decline syndrome, allometric ratio method, S42

Dianthus caryophyllus, vascular wilt, diversity in field, Argentina, 661

Diaporthe phaseolorum, on soybean, molecular and genetic variability, South Dakota, S114

Dick, R. P., S125

Dickman, J., S91

Dickman, M. B., S16

Didymella spp.

-D. bryoniae, on cucurbit, pesticide effect, S50

-D. rabiei, mating-type distribution, in Tunisia, S87

Dieguez-Uribeondo, J., S25

Diguistini, S., S8

Dillard, H. R., S26, S95

Dill-Macky, R., 766

Ding, S. W., S90, S131

Dionne, I., S26

Disease control, fish emulsion, soilborne and foliar plant pathogens, S2

Disease detection, conductive polymer analyses, electronic aroma technology, 419

Disease forecasting, weather data, high-resolution, S53

Disease management

— arbuscular mycorrhizae, role, S126

- cover crop decomposition, soil pathogens, S126

-forest managers, field, S64

Disease-warning system, leaf wetness, empirical models, S52

Diver, S., S137

Dixelius, C., 743

Dixon, P. D., S22

Dixon, P. M., S28, S40, S41

Djonovic, S., S26

do Amaral, A. L., S23

Docampo, D., S83

Dodds, J. A., 1337, S138, S153

Dogwood (see also Cornus florida)

- powdery mildew, molecular analysis, S95

Dolan, M., S135

Dollet, M., S134

Domier, L. L., S40, S61, S67, S84, S99, S159

Dominiak, J. D., S141

Don, L. D., 454

Donahoo, R. J., S77

Dong, H.-S., 1048

Dong, R., S42

Dong, S., S159

Dong, Y., 766

Donofrio, N., S26, S122, S135, 1032

Doohan, D. J., S74

Dopkins, D. M., S39

Dorrance, A. E., S21, S70, S84

Doster, M. A., S26

Douches, D., S2, S54, S158, S160, S161

Dowkiw, A., 1358

Driever, G. F., S70

Driks, A., 1244, 1249

Driscoll, B. T., S165

Druffel, K., S81

Dry, I. B., 438, S33

Duan, Y. P., S14, S26, S27

Dubcovsky, J., 1198

Dufault, N. S., S164

Dufour, J., S8

Dugan, F. M., S27

Dulla, G., S27

Dumenyo, C. K., S41, S152

Dumroese, R. K., S99

Dunbar, R. W., S139

Duncan, R. A., S31, S151

Duniway, J. M., S39

Dunkle, L. D., S30

Duplessis, S., S133

Dupper, G. E., 751

Durán, P., 875
Durel, C.-E., 370

du Toit, L. J., S26, S85

Duval, J. R., S94

Dyer, A. T., S160

Dyer, P. S., S87

Dzengeleski, S. I., S157

Eastburn, D., S67, S139

Eastwell, K. C., S57

Edel-Hermann, V., 661

Edmonds, R. L., S27

Education (see Teaching)

Edwards, R. M., S104

Egel, D. S., S27

Eger, J. E., S145

Eggenberger, A. L., S38

Egolf, R., S55, S85

Ehret, G. R., S86

Ehrharta villosa, leaf gall nematode, bacterial association, toxins, S88

Eichenlaub, R., S123

Eichhorn, H., S122

Eilam, T., 94, 569

Eisenman, H., S132

Eizenga, G. C., S96

Ekramoddoullah, A. K. M., 1235

Ekwamu, A., 743

Elad, Y., S59

El-Allaf, S. M., 1342

Elazegui, F. A., 672

Electron spin resonance, nitric oxide detection in plants, 402

El-Hamalawi, Z. A., S27, S98, S151

Elicitor

- cerebroside, disease resistance to Fusarium, 813

—pea gene, coding, 651

-Trichoderma virens, strains, 171

Elizabeth, S. V., S27

Elliott, D. R., S57

Elliott, M., S27

Ellis, M. A., S76

Elmer, W. H., S164

El Yacoubi, B., S14

Embellisia sp., on Astragalus lentiginosus, localization, S69

Ender, M., S157

Enderle, C., S96

Endophyte, biocontrol agent, Verticillium yellows on Chinese cabbage, 412

Endres, G., S10

Engle, J. S., S28

English-Loeb, G. M., S70

Enis, J. N., S25

Enterobacter clocae, on cucumber and pea, metabolism, S88

Enterobacteriaceae, gall-forming species, cranberry, 1164

Epidemics

-aerobiological information, meteorological trajectory analysis, prediction, S130

-binary, fractal-based sampling, 1215

Epstein, L., 388

Erhardt-Zabik, S., S113

Ermacora, P., 203

Errata

-vol. 92, no. 11, 2002, 120

—vol. 94, no. 6 (suppl.), 2004, 796

—vol. 94, no. 6 (suppl.), 2004, 912

—vol. 94, no. 6 (suppl.), 2004, 1031

Erselius, L. J., 154

Ersoz, E. S., S133

Erwinia spp., factors affecting lethal actions, 76

-E. amylovora: on apple, resistant rootstocks, S62; on apple, temperature and flower age, 901; on apple and pear, biocontrol with bacteria, iron bioavailability, 1286; on apple and pear, growth inhibition, viral lysozyme, 1315; on nonhosts, epiphytic growth, S152; plasmid pEA29, genetic analysis and virulence, S68; on 
rosaceous plants, gene identification, S116

-E. betavasculorum, on sugar beet, root necrosisinducing ability, S55

-E. carotovora: biofilm formation, cellulosecoated surface effect, S9; biofilms, antibiotics and biocides, S66; on Chinese cabbage, biocontrol with Bacillus, S19; genomic plasticity, S162; quorum sensing, S16

-E. chrysanthemi: hrp regulon, analysis, S113; hrp up-regulated virulence genes, S95

-E. tracheiphila, on Cucumis melo, epiphytic survival, S22

Erysiphales, taxonomic diversity, Pacific Northwest, S35, S152

Erysiphe necator

- detection by PCR and primers, S151

-on grape, genetic analysis in Italy, 544

Escalante, M., S92

Eskalen, A., S28, S57, S151

Eskandari, F., S142

Esker, P., S10, S28

Eskridge, K., S65

Esposito, B., S68

Estevez de Jensen, C., S144

Eucalypus spp.

-Coniothyrium zuluense, phylogency and DNA sequence, $\mathrm{S} 21$

-crown decline, organisms associated, S42

Eugster, C., S50

Euphorbia ringspot virus, detection and characterization, S36

Eutypa lata, distribution and host range, California, S155

Evans, C. K., 766

Evans, T. A., S24

Everts, K. L., 832, S28, S116

Evolution

- coevolution fungus and plants, early terrestrialization, S119

- endophytes and host specialization, S119

-fungal pathogens and host specialization, 789

- geological time, evolutionary rates, and fungi, S120

— humans and plant disease, S119

-plants and arbuscular mycorrhizal fungi, interactions, S119

-tree pathogens, speciation and host pathogen co-evolution, S119

Exserohilum turcicum, on maize, conidiation repression by blue light, $\mathrm{S} 30$

Eyles, A., S102, S110

Ezra, D., S36

Fahleson, J., 743

Faize, L., 604

Faize, M., 604

Fakhoury, A. M., S28

Falacy, J. S., S151

Falconi, C. E., S28

Falk, B., S75, S90, S100, S131

Fan, J. H., S43

Fan, Z. F., S29

Faris, J. D., 1056, 1061, S32

Farman, M. L., S87, S135

Farr, D., S27

Farrar, J. J., S29

Farrokhi, F., S91, S92

Faure, A., 370

Favali, M. A., 203

Favery, B., 289

Fazio, G., S62, S68

Feau, N., S29

Febres, V. J., S29

Fegan, M., S121

Feng, C., S44, S45

Feng, D.-X., 289

Fenn, P., S45

Fenton, J., S47, S156

Ferguson, L. (Calif.), 388

Ferguson, L. M. (N.C.), 892, S10, S57, S63
Fermin, G., S151

Fernandez, G. E., S57

Fernandez, L., 672

Fernando, W. G. D., S18, S115, S116, S141

Ferrandino, F. J., 1215, S164, S165

Ferrin, D. M., S29, S76, S153, S154

Ferro, C. R., S29

Fertilizer, bovine manure, vegetable contamination risk, $\mathrm{S} 127$

Fery, R. L., S8, S102

Fessehaie, A., S30

Fichtner, E. J., 780

Ficke, A., 438

Figueroa, M., S135

Figueroa-Lopez, P., S30

Filgueira, J. J., S31

Finlay, M., S140

Fischer, K. S., 672

Fish, W. W., 337, S168

Fitt, B. D. L., 789

Fjellstrom, R.G., 296

Flaherty, J. E., S30

Flanders, K. L., S9

Fleer, J. M., S30

Fletcher, J., 18, S47, S73, S115, S170

Flier, W. G., 154, 613

Floriculture, nematode association, Florida, S19

Foliar pathogens, tropical fungi, S38

Folimonov, A., S30, S131

Folimonova, S., S20, S30, S131

Food safety, food-borne pathogens, S127

Foor, S., S96

Forbes, G. A., 154, S101

Forensics

—microbial, epidemiology, S124

- molecular clues, evolution, and phylogeny, S124

- pathogen portal project, data and tools, S124

- plant pathogen, S124

- protocol, threatening plant pathogens, S77

- Pseudomonas syringae, model for study, S124

Forest

- diseases in Uganda, S74

- management, wood decomposition in soil and

fungi, northwestern USA, S88

-tree resistance, quantitative inheritance, S133

Formento, N., S44

Forrest, R., 280

Förster, H., 163, S25, S31, S97, S149, S151

Fortnum, B. A., S144

Fory, L., S135

Foster, K. A., S56

Fought, L., S31

Fouly, H. M., S132

Foune, C. L., S31

Fraaije, B. A., S20, S31

Fragaria chiloensis latent virus, nucelotide sequence, phylogenetic analysis, S104

Fraile, A., 992

Franc, G. D., S24

Franceschi, V. R., S133

Francis, D., S123

Francis, M., S31, S61

Francl, L. J., 1007, S72

Franco-Lara, L., S31

Frankliniella spp., Tomato spotted wilt virus vector, acquisition, 333

-F. occidentalis, Tomato spotted wilt virus vector, host suitability, 706

Frantz, J. M., S62

Frate, C. A., S31

Fraxinus sp. (see also Ash)

- phytoplasma, disease association, Colombia, S31

Frederick, R. D., S19, S64, S69, S85

Freeman, M., S17, S36

French, R., 772, S6, S32, S88, S99, S106

French-Monar, R. D., S144

Frick, M., S63

Friesen, T. L., 1056, 1061, S28, S32
Fritz, A. K., 961

Fritz, D., 1245

Frost, K. E., S32

Froud, K. J., S57

Fry, W. E., S68, S87

Fucikovsky, L., S144

Fuentes-Davila, G., S30

Fujishige, N. A., S32

Fukuda, S. K., S9, S149

Fukui, R., S49

Fulbright, D. W., S65

Fumigant

-iodomethane, methyl bromide alternative, strawberry and tomato, S149

-isothiocyanate, toxicity, S112

Fumigation

- forest nursery, alternatives, S152

—-soilborne and seed pathogens, S36

Funabara, M., S101

Fungicides (general) (see also Fungicides, specific)

-Bayer CropScience, S31

-biorational, S72

— geranium diseases, combination with yeast, 196

- grape black rot, spray timing, 641

- helicopter application, drift evaluation, S165

- picolinamides, mode of action and physical properties, S113

-resistance evolution, experimental populations, S45

— screening technique, natural products, S167

- seed application, watermelon and cantaloupe, gummy stem blight, S94

- spiral gradient dilution, growth responses, 163

Fungicides (specific) (see also Fungicides, general)

-boscalid, crop quality and physiology, S45

- CAY-1, small fruit diseases, S148

-dicarboximide, Botryotinia fuckeliana, osmosensing histidine kinase, 1129

-famoxadone and cymoxanil: fungi and bacteria on vegetables, S95; on tomato, S110

-FD141, analogs, germination effect on fungi, S143

-fenamidone, vegetables and potato, S146

- methyl bromide, vegetable farm application, S16

-Quintec 2SC and Gavel 75DF, performance in southern USA, S145

—strobilurin, pyraclostrobin, physiological effect, S44

-Tanos, chemistry, disease control, S33

Funnell, D. L., 1178, S32, S125

Furman, L. A., S165

Fusarium spp., on corn kernels, fumonisin, resistance sources, 251

-F. circinatum, on Monterey pine, resistance, S3

$-F$. graminearum: on barley, deoxynivalenol accumulation, host effect, 766; on barley, resistance and deoxynivalenol accumulation, 1145; on corn residue, mycotoxin in wheat, S79; genes in inoculum development, analysis, S159; genomics on wheat and barley, S122; on grasses, genomic analysis, S35; hyphal differentiation genes, S161; RNA interference, S68; vegetative compatibility group, barrage zone formation, 432

-F. moniliforme, on cotton, hardlock, southeast USA, S145

-F. oxysporum: on carnation, field diversity, Argentina, 661; cerebroside elicitor, disease resistance, 813; on chickpea, integrated management, biocontrol, factors, 946; on chickpea, race evolution, fingerprinting, 228; inactivation by solarization, moisture effect, 132; on Koa, diversity in Hawaii, S4; on lettuce, genetic variation, S68; on melon, race 1.2, polygenic inheritance, 1331; on tomato, suppression in growth media, predictive factors, 1094; in tree nurseries, early detection, S99; on watermelon, quantification resistance, 832; on watermelon, race 2 in Indiana, S27; on watermelon, regional 
populations, S116

-F. pseudogramminearum, genetic variation in field, S7

-F. solani: on bean and soybean, soil bulk density relation, S144; on soybean, mycovirus infection, S67; on soybean, PCR detection, in roots and soil, S60; on soybean, penetration study, S74; on soybean, root necrosis, S162

-F. verticillioides, on corn, chitinase for control, molecular evolution, S74; on corn, migration, $\mathrm{S} 113$; on corn, phytoanticipin tolerance, S80; history and taxonomy, perspectives, S120; on maize, Bacillus mojavensis competition, 796; on maize, kernel infection, fumonisin, 88

Fusicoccum sp., on Pacific madrone, new species, S27

Fyffe, A. E., S32

Gabriel, D. W., 61, S14, S26, S27, S87

Gadoury, D. M., 438, 641, S33, S50, S70, S76

Gaeumannomyces sp., morphology on roots, $\mathrm{S} 132$

-G. graminis: on cereals, varietal characteristics, S102; on creeping bentgrass, pathogenicity, S102; on wheat, host growth model, 535

Gai, X., S71

Gaitán, S. L., S31

Galadima, N., S135

Galagan, J., S122

Galbraith, D. W., S109

Galdames, R., 875

Gale, G., S140

Gale, L. R., S122

Gallegos-M, G., S143

Galloway, H., S151

Galvani, C. D., 1031

Ganske, D., S66

Gao, B., S25, S33, S82

Garavito, A., S135

Garbelotto, M., 1075, S40

Garcia, E., S61

García-Arenal, F., 992

Garcia-Pedrajas, M. D., S33, S73

Garcia-Rivera, J., S132

Gardais, S., S14, S109

Gardiner, E. S., S110

Garnsey, S. M., S30, S92, S130

Garrett, K. A., 961, 999, 1013

Gartemann, K.-H., S123

Garvin, D. F., S33

Garzon, C. D., S33

Gassmann, W., S56, S115

Gaudet, D. A., S63

Gautheron, N., 661

Gay, P. A., S18, S151

Gbur, E. E., S89

Ge, Y., S60

Geary, B. D., S71

Gebhardt, C., 370

Gebre-Selassie, K., 345

Geddens, R., S33, S95, S110

Geider, K., 1315

Geiser, D. M., S117

Geldenhuis, C. J., S89

Gene

-Am, Alfalfa mosaic virus in tomato, location on chromosome 6, 345

-apple scab, resistance locus, 370

-Bct, Beet curly top virus on bean, 320

-DRR206, pea promoter, elicitor-coding, 651

- hrp, olive and knot formation, 484

-Lr26, Puccinia triticina on wheat, 632

- Pi7 $(t)$, rice to blast, 302

- Pi-ta, rice, blast resistance, 296

-Rep, Tomato yellow leaf curl virus, 490

- Rpc1, barley crown rust, molecular mapping, 858

-Stb4, Septoria tritici blotch on wheat, 1198

- Vf, apple to scab, 364

Gene ontology, terms, bacterial pathogens and pathogenesis, S20
Genin, S., S121

Genome, sequences, gene $\mathrm{KO}$ mutant, in fungi, S51

Genomics

- comparative, core fungal genes, S42

- organism choice for sequencing, letter to editor, 800

-role, scientists and society, presidential address, 18

Genswein, B., S63

Gent, D. H., 184, S33, S34, S56

Gepts, P., 593

Gera, A., S134

Geranium

-bacterial wilt, chemical screening, S77

-Botrytis cinerea, fungicides and phylloplane yeasts, 196

-Xanthomonas campestris, leaf surface distribution, S34

Gergerich, R. C., 111, S116

Gerhardt, S. A., S4

Gerik, J. S., S34

German, T. L., 759

Gessler, C., S50

Gevens, A. J., S157

Ghabrial, S. A., 722, S114, S158

Ghosh, D., 912

Ghoshroy, S., S91

Giammaria, S. L., S34, S144

Giannetti, C., S34

Gibberella zeae

- genetic maps, S58

- perithecia, temperature and moisture effect, S164

- splash dispersal factors, S82

-spore deposition and spatial pattern, corn and wheat field, S93

—-spore release and viability, techniques, S93

-on wheat: genetic mapping, 520; rain splash dispersal, Ohio, 1342

Gibbons, J. H., 819

Gibson, D., S106

Gieco, J. O., 1198

Giesler, L. J., S83, S117, S162

Gilbert, J., 432

Gilbertson, R. L., 593, S17, S37, S70, S85, S117, S134

Gilchrist, D. G., S109

Gildow, F. (Md.), 868

Gildow, F. E. (Pa.), S24, S134

Giles, K., S170

Gillaspie, A. G., S34

Gillett, J. M., S161

Gilligan, C. A., 209, 535

Gilmore, B., S19

Gilpert, J., S96

Ginseng, Cylindrocarpon root rot, iron role, S86

Gisler, S., 1189

Gitaitis, R. D., S34, S94, S145

Glasheen, B. M., S164

Glasner, J. D., S83

Glawe, D. A., S35, S152

Glazebrook, J., S122

Gleason, M. L., S22, S40, S41, S52, S53, S100, S102

Glenn, A. E., S80

Glogoza, P., S69

Glukhova, L. A., S35

Gobbin, D., S50

Gochez, A. M., S6

Godfrey, D., 438

Goeke, S. C., 111

Goerre, M., 370

Goes da Silva, F., S135

Goff, S., S65

Goffinet, M. C., S22

Gognalons, P., 345

Goh, Y.-K., S158

Goheen, E., S35, S48

Gold, S. E., S33, S73, S101
Goldbach, R. W., 706

Goldberg, N. P., S63

Goldman, P. H., S12, S150

Goldman, S. L., S115

Golino, D., S2, S61

Gomez, L., S35

Gonçalves-Vidigal, M. C., S158, S162

Gong, F. C., S109

Góngora-Canul, C., S35, S52

Gonsalves, D., S151

Gonzalez, M. C., S38

González-G, E., S143

Gonzalez-Jaén, M. T., S64

Goodin, M., S103, S123, 912

Goodwin, S. B., 800, 1198, S2

Gopal, K., S35

Gopi, V., S35

Gordon, T. R., S3, S149, S154

Goregaoker, S., S122

Gossen, B. D., 236

Goswami, R. S., S35

Gottwald, T., 1390, S9, S23, S81, S130, S131, S137

Gould, A. B., S36

Gowda, S., S131

Grabosky, J., S36

Graef, G., S65

Grafton, K. F., S107

Graham, J. H., S25

Grape

-Armillaria root disease, cultural control, S7

-bitter rot, factors, S71

_black rot, factors and spray timing, 641

-Botrytis cinerea: biocontrol with plant volatiles, 924; flower infection, 850; nitrogen and relative humidity effect, S117; risk for strawberry, in California, S11

- downy mildew: metalaxyl translocation, S50; phosphite action, S110; survival in field, S50

-endophyte, Xylella fastidiosa, S8

-Eutypa dieback: boron for control, S89; systematics in California, S154

- fungicides, California, S106

-Grapevine rupestris stem pitting virus, two strains, S61

— gray mold, postharvest treatment, S71

- leafroll virus complex, molecular characterization, S2

-marafivirus, new, S90

- organic farming, Pavich family, S126

-Phomopsis cane and leaf spot: fungicides in post-infection control, S76; lime sulfur and copper to control, S76

-Pierce's disease: severity and rootstock relation, S15; spatial pattern analysis, California, 1136

- powdery mildew: control in California, S57; host barriers, 438; population biology, Italy, 544

Grau, C. R., S161

Gravel, V., S164

Gray, F. A., S152

Gray, S., S12, S58, S71, S134, S163

Greene, D. W., S142

Greene, I. D., S34

Grégoire Valentini, S., S165

Gregos, J., S2

Gremillion, S. K., S145, S168

Greve, L. C., S89

Grimme, E., S36

Grisham, M. P., S36

Groenhof, A. C., 280

Groose, R. W., S152

Gross, D. C., S63, S107

Gross, P. L., S107

Groth, J. V., S79

Grove, G. G., S151

Grove, M. D., S141

Groves, R., S17, S36

Grube, R. C., S36

Grunden, E., S65, S158

Grunwald, N., S47, S126 
Gryzenhout, M., S74

Gu, Y.-H., S125

Guan, J., S83, S158

Guaragna, M. A., S36

Guava, plant disease study, model, S50

Gubler, W. D., S28, S57, S89, S151, S154, S155

Gudelj, I., 789

Gudmestad, N. C., 1368, S58, S156

Guérin, F., 364

Guerra, G., S44

Guerra-Moreno, A. S., S37

Guerrero-Prieto, V. M., S67

Guignardia spp.

$-G$. bidwellii, on grape, fungicides and factors, 641

- G. citricarpa, on citrus, detection protocol in fruit, S83

Guillin, E., S44

Guiltinan, M., S6

Guimaraes, R. L., S37

Gunduz, I., 687

Gunkel, C., S45

Guo, B. Z., S64

Guo, P., 402

Gustus, C., 766

Gutierrez, L., S37, S69, S158

Gutiérrez-Espinosa, M. A., S35

Guyon, D., 125

Guzmán, P., 593

Gymnosporangium spp., phylogeny, morphology, S114

Haddad, F., S37

Hadwiger, L. A., 651

Hagan, A. K., S13, S37

Hagen, C., S37

Hagler, W. M., 88

Hajimorad, M. R., S38

Halik, S., S163

Halverson, L. J., S15, S105

Halvorson, M., S10

Hamada, W., S159

Hamasaki, R. T., S9, S149

Hamel, P. B., S110

Hamelin, R. C., S29, S127

Hamilton, G., S36

Hamm, P. B., S71, S152

Hammerschmidt, R., S2, S42, S54, S156, S157, S158, S160, S161

Hammond, J., S38

Hammond, R. (Ohio), S84

Hammond, R. W. (Md.), S116, 912

Hammond, T. M., S38, S68

Han, B., S135

Han, D. Y., S38

Han, S. S., S52

Hanlin, R. T., S38

Hanna, J. W., S38

Hanna, L., S90, S102

Hansen, E., S16, S35, S48

Hansen, J. M., S98

Hansen, M. A., S38

Hanson, B., S10

Hanson, L. E., 171, S24, S150

Hanson, S. F., S4, S98

Hanzawa, S., S101

Hao, G., S39, 1031

Hao, J. J., S39

Harakava, R., S83

Harikrishnan, R., S27, S39

Harman, G. E., 147, S138

Harness, A. M., S1, S39

Harrington, T. C., S100, S160

Harrison, L. A., S39

Hartitz, M., S150

Hartman, G. L., S29, S60, S61, S159

Hartman, J. R., S73

Hartung, J. S., S56, S60

Harwood, R., S129

Hasegawa, H., S16, S40
Hasenstein, K. H., S51

Hashiba, T., 412

Hashim, J. M., 1136

Haudenshield, J. S., S40, S99

Hausbeck, M. K., S13, S156, S157, S158, S161

Hawes, M. C., S14, S109

Hay, F. S., S18

Hayakawa, T., S103

Hayden, K. J., 1075, S40

Haygood, R. A., S145

Haynes, J. L., S85

Hayward, A. C., S121

He, S. Y., S59

Heath, M. T., S145

Heath, R. N., S74, S89

Hebbar, P. K., S25

Heer, W. F., 961

Hegedus, D. H., S12

Heick, J. A., S153

Heist, E. P., 1178

Helianthus annuus, disease resistance, wild population, $\mathrm{S} 8$

Helland, S. H., S22

Hemicriconemoides spp., differentiation and molecular characteristics, S76

Hemileia vastatrix, antagonists for, screening, S37

Henderson, D., S40

Hendrix, F. F., Jr., S143

Henning, S. W., S132

Henson, B., S10

Heo, S. H., S40

Hermansen, A., S76

Hernandez, A. G., S159

Hernandez, S., S10, S40, S41

Hernandez-Bello, M. A., S41

Hernández-C, F. D., S143

Hernández-Guzmán, G., S152

Hernandez-Martinez, R., S41, S152

Herrera, C. M., S41

Herrero, S., S41

Hess, N. J., S107

Heterobasidion annosum

- on Christmas trees, Pacific Northwest, S24

- on fir Christmas trees, keepability, S16

Heterodera spp.

- H. glycines: esophageal parasitism, analysis, $\mathrm{S} 25$; on soybean, parasitism genes, RNA interference, $\mathrm{S} 100$

-H. schachtii: on beet, parasitism genes, S82; soil suppressive factors, $\mathrm{S} 78$

Hibi, T., 244, 683

Hibiscus, tobamoviruses, new, S3

Hibiscus latent Fort Pierce virus, detection, New Mexico, S4

Hiddink, G. A., S105

Hiebert, E., 490

Higgins, R., S65

High Plains virus disease, in sweet corn, seed transmission, $\mathrm{S} 8$

Hilf, M. E., S30, S131

Hill, A. L., S150

Hill, C. B., S29

Hill, J. H., S38

Hill, J. P., S8, S150

Hill, S., S158

Hillman, B. I., S84, S164

Hilson, P., 759

Hinton, D. M., 796

Hintz, W. E., S8

Hirata, K., 454

Hirsch, A. M., S32

Hirsch, J., 289

History

-bacteriology and plant pathology, 19th century, S139

-Fischer-Smith debate, controversy reconsidered, S140

- phylloxera grapevine disaster, France, S140

- soil bacteria, ecology, social cooperation, S140

-William Farlow Laboratory, institutional cryptogamy, S140

Hjeljord, L. G., S41

Ho, H. H., S41

Ho, K. M., 1145

Hoch, H. C., 1031

Hofer, D., S7, S149

Hoff, T., S107

Hoffman, L. E., 641, S96

Hogenhout, S. A., 842, S4, S103, S123, S134

Hoitink, H. A. J., S138

Holbrook, C. C., S18, S48

Holley, R., S113

Hollingsworth, C. R., S152

Hollister, E. C., S158

Holm, R. E., S17

Holmes, G. J., S130

Holub, E. B., S107

Homalodisca coagulata, vector for Xylella fastidiosa, on grape, California, 1136

Homeland security, crop biosecurity, crop protection, 419

Honda, Y., S44

Honeycutt, C. W., S77

Hong, C. X., S6, S14, S54, S55

Hong, S. G., S42, S114

Honjo, H., S49

Honorato, R., 875

Hooper, R. J., S42

Hopkins, D. L., S87

Horgen, P. A., S8

Horvais, R., 578

Horvath, B. J., S42, S159

Hourani, H., S2

House, B. L., S93

Howard, R., S42

Howd, D. S., 978, S37

Howell, C. R., S26, S138

Howell, D. R., 171

Hoy, C. W., 842

Hoy, M. W., S19

Hsiang, T., S42

Hsieh, C.-Y., 1031

Hsu, H. T., S3

Hu, B. H., S60

Hu, J. S., S9, S149, S154, 1031

$\mathrm{Hu}, \mathrm{R} ., \mathrm{S} 61$

Hu, X., S42

Huang, G., S42

Huang, Q., S43

Huber, D. A., S133

Huber, D. M., S103

Huckaba, R. M., S145

Hudson, L. C., S43

Hughes, G. (UK), 138, 999, S137

Hughes, T. J., S43

Huitema, E., S159

Hulbert, S., S48, S90

Humulus lupulus, powdery mildew, spatial pattern analysis, Pacific Northwest, sampling, 1116

Hunger, R. M., S170

Hunt, T. E., S117

Hussey, R., S25, S33, S42, S82, S100

Hwang, D. H., S52, S53

Hwang, I., S46

Hyakumachi, M., S103

Hyder, N., S43, S108

Hypersensitivity, harpin expression, transgenic tobacco, pathogen defense, 1048

Iamauti, M. T., S79

Idris, A. M., 1068, S11, S43, S150

Ignatov, A. N., S43, S67

Ikeda, K., 561

Immunochromatographic devices, diagnosis of viral nucleic acid, S39

Impatiens necrotic spot virus, in New Zealand, outbreak, S57

Incorvia-Mattina, M. J., S165

Ingham, S., S127

Inglis, D. A., S44 
Inguagiato, J. C., S164

Inman, S., S109

Inoue, I., S44

Inoue, Y., 478

Integrated Pest Management

-barriers, safe pesticides, developing countries, S38

- crop pest survey in North Dakota, information delivery, S69

Inula viscosa, disease controlled by extracts from, 1042

IR-4

- fungicide registration, update, S103

- tropical crops, registration, S150

Iris yellow spot virus

-on onion, management, genotype, and chemical treatment, S34

-on onion seed and bulbs, S153

Irish, B. M., S44

Isakeit, T., S146

Isard, S., S44, S65, S130

Ishida, M. L., S44, S59

Ishii, H., 604

Ishikawa, K., S44

Ishimaru, C. A., 184, S33, S123

Ishizaka, M., 604

Islam, S. Z., S5, S44

Isobe, C., 454

Ivancovich, A., S44, S158

Iwata, M., 813

Jabaji-Hare, S., S165

Jabs, T., S44, S45

Jackman, A., S100

Jackson, E. W., S45

Jackson, M. A., 1267, S115

Jacobi, V., S8

Jacobs, F. H. H., 463

Jacobs, J., S156

Jacobs, K., S45, S163

Jacobsen, B. J., 1272, S5, S36, S117

Jaime, M. D. L. A., S45

Jaime-Garcia, R., S45

Jambois, A., S133

James, R. L., S99, S152

Janeau, J. L., S92

Jang, C. S., S45

Jang, K. S., S59

Janisiewicz, W. J., S20, S45, S46

Jansky, S. H., S32

Jantasuriyarat, C., S46

Järlfors, U., 722

Jaudzems, V. G., 850

Jeffers, S. N., S39, S81, S118

Jeffries, P., S112

Jeger, M., S112

Jellison, J., S93, S165

Jensen, B., 551

Jensen, D. F., 551

Jensen-Tracy, S. L., S97

Jeon, Y. H., S15, S46

Jeung, J. S., S26, S46

Ji, P., S46

Jia, H., S159

Jia, Y., 296, S47, S96, S107, S111

Jiang, X., S29

Jiménez-Diaz, R. M., 228, 946

Jiménez-Gasco, M. M., 228, S117

Jimenez-Hidalgo, I., S47

Jin, Y., 858

Jo, Y., S159

Jochua, C., S47

Johnson, C. S., S47

Johnson, D. A., 380, 737, S44, S71, S76, S152

Johnson, E. G., S106, S123

Johnson, K. B., 1286, S152

Johnson, P. G., S15

Johnson, V. L., S89

Johnston, M. R., S5, S117

Jojoba, diseases, Australia, S163
Jomantiene, R., S116, S123

Jones, A. D., S55, S117

Jones, D., S168

Jones, J. B., 177, S6, S46, S88, S144, S146

Jones, M. A., S69

Jones, R. W., 44, 1031

Jones, S. S., 932

Jong, J. L., S17

Joost, P. H., S6

Joosten, N. N., 706

Jordahl, J. J., S97, S107

Jordan, D. L., S82

Jordan, K. S., S47

Jordan, R. L., S36

Jorge, V., 1084

Joshi, B. D., S47

Joshi, M. V., S48, S123

Joshi, R., S69

Judelson, H., S48, S53, S101

Jung, G., S2, S14, S15, S23

Jung, H.-Y., 244, 683

Jurgensen, M. F., S88

Jurgenson, J. E., 520, S58

Jurick, W. M., II, S88

Jurjevic, Z., S48

Kabbage, M., S48

Kadooka, C., S104, S155

Kahlke, C. J., S145

Kahmann, R., S122

Kahn, M. L., S93

Kainz, M., 759

Kaiser, R., S31, S146

Kakizawa, S., 244, 683

Kaku, H., 478

Kaloshian, I., S112

Kamenova, I., S3, S4, S48

Kamgan Nkuekam, G., S89

Kamo, K., S3

Kamoun, S., S24, S123, S136, S156, S159

Kanaskie, A., S35, S48

Kanematsu, S., 561

Kaneshiro, W. S., S49, S152, S155

Kanetis, L., 163, S49, S97

Kang, H. G., S55

Kang, K. Y., S52, S53

Kang, L., S49

Kang, S., S3, S51, S52, S53

Kang, Y., S49

Kaniewski, W. K., S154

Kankanala, P., S136

Kapadia, N. N., S32

Kaplan, D., S130, S138

Kaplan, I., S58

Karasev, A. V., S49, S55, S85, S111

Kasuya, M., S49

Katan, J., 132, S59

Kaufmann, P., S16

Kaur, S., 388

Kavitha, K., S115

Kawate, M., S150

Keen, N. T., S95

Keever, T., S65, S130

Keinath, A. P., S50

Keith, L. M., S50, S152

Keith, R., S151, S152

Kelemu, S., S50

Keller, B., 1036

Keller, H., 289

Keller, K. E., S104

Keller, M., 850

Keller, N. P., S38, S68

Kelly, J. D., S157, S158, S162

Kema, G. H. J., 261

Kemerait, R. C., S50, S170

Kemmitt, G., S78, S79

Kendra, D., S120

Kenerley, C. M., S26

Kennedy, G. G., S100

Kennelly, M. M., S50
Kentucky bluegrass, necrotic ring spot, cultivar reaction, $\mathrm{S} 2$

Kers, J. A., S48, S51, S123

Khan, J., S51

Khan, M. F. R., S51

Khan, N. I., S51, S93

Khan, V. A., S32

Khang, C. H., S51

Khayum, S., S35

Khosla, R., S34

Kiewnick, S., S51

Kilaru, A., S51

Killham, K., 351

Kim, B. R., S52

Kim, B.-S., S19

Kim, H. G., S40, S45, S61, S113

Kim, H. J., S52, S53

Kim, J. S., 111

Kim, J.-C., S59

Kim, K.-H., 1295

Kim, K. R., S53

Kim, K. S., 111, 970, S48, S52, S53

Kim, K. W., 970, S52

Kim, M.-S., S38, S88, S99

Kim, S., S3, S53, S81

Kim, S. B., S81

Kim, S. G., S15, S46, S52, S53

Kim, S. T., S52, S53

Kim, Y. H., 1295, S15, S46

Kim, Y. K., S52, S53, S54

Kinloch, B. B., Jr., 751

Kinter, M., S123

Kiraly, L., S14

Kirk, W., S2, S54, S78, S109, S157, S158, S160, S161, S162

Kirkpatrick, B., S89

Kirkpatrick, T., S72, S89, S147, S169, S170

Kistler, H. C., S35, S122

Kita, N., 730

Kleinhenz, M. D., S74

Kleinkopf, G., S96

Kleinschmidt, C. E., S54, S120

Klepaski, J., S157

Klessig, D. F., S55

Kliebenstein, D. J., S112

Kliejunas, J. T., S79

Kloepper, J. W., 1259

Klopfenstein, N. B., S38, S88, S99

Klopmeyer, M. J., S138

Klosterman, S. J., 651

Kluepfel, D. A., S144

Knudsen, G. R., 1383, S79

Knudsen, I. M. B., 551

Knudson, D. L., S123

Ko, T. S., S61

Kobayashi, D. Y., S12

Koczan, J. M., S56

Koehn, A. C., S99

Koenig, R. L., S137

Koga, J., 813

Köhle, H., S44

Kohler, A., S133

Kohn, L. M., S45, S47, S65

Kohout, M. J., S54

Koike, N., 604

Koike, S. T., 569, S12, S150

Koizumi, S., S44

Kokkinos, C. D., S19, S54, S105

Kolade, O. O., S59

Kolakowski, J. E., S96

Kolli, V. S. K., S122

Kolmer, J. A., S77, S79

Kolomiets, M., S75, S114

Kong, P., S54, S55

Koprowski, H., S49, S55, S85

Korsten, L., S83

Kositratana, W., S19

Kosman, E., 632

Kosted, P. J., S4

Kots, N., S12 
Koutsoudis, M., S41

Kox, L. F. F., 613

Kratochvil, R. J., S28

Kraus, J., S55

Kriticos, D. J., 805

Kritzinger, Q., S55

Kritzman, A., S134

Kritzman, G., S12

Kroon, L. P. N. M., 154, 613

Kropp, B. R., S155

Kruger, W. M., S114

Kubo, Y., 478

Kucharek, T. A., S168

Kuga-Uetake, Y., 561

Kulakiotu, E. K., 924, 1280

Kuldau, G. A., S55, S117

Kulemeka, B. P., S39

Kumar, D., S55

Kunkel, D. L., S17, S103, S150

Kuperman, R. G., S96

Kupferberg, E., S139

Kurdyla, T., S5

Kurle, J., S97, S144, S159

Kurnas, C. W., S96

Kurtzweil, N. C., S161

Kusaba, M., 454

Kuykendall, L. D., S55

Kwak, D. W., S113

Kwon, C., S161

Kwon, S. I., S56

Labavitch, J., S89

Labbé, C., 177

Labonne, G., 1390, S23

Labuschagne, L., S89

Lacava, P. T., S56

Laemmlen, F., S108

Laflamme, G., S164

Lahey, K. A., S56

LaHue, S. S., S67

Laine, J., S48

Lalancette, N., S56, S165

Lalla, S., S105

Lamari, L., S22

Lamb, J. A., S98

Lamb, J. F. S., S5

Lambrecht, P. A., S73

Lamondia, J. A., S165

Lamotte, R., 280

Lamour, K., S158

Lampe, D., S8

Lamppa, R. S., S25, S39

Lan, Z., S56

Landa, B. B., 946, S4, S24

Lane, L. C., S83

Lang, J. M., S56

Langham, M. A. C., S19, S157

Langston, D. B., S102, S147

Langston, V. B., S145

Lannou, C., 712

Lapeyrie, F., S133

Larget, B., 737

Larkin, R. P., S56, S77, S125, S163

Laroche, A., S63

Larsen, R. C., 320, S57, S153

Larson, B. J., 1272

Lartey, R. T., S57

Lashomb, J., S36

Latham, S. R., S28, S57, S151

Lauzon, C., S8

Lawrence, C. B., 184, S22, S42

Lawrence, K. S., S80

Lawson, T. J., S164

Lazarovits, G., S2

Leach, J. E., S61, S65, S90, S135

Leahy, K. P., S142

Leandro, L. F., S57, S94, S100

Leavitt, G., S57, S106

Lebas, B. S. M., S57

Le Cam, B., 364
Lecomte, P., 289

Lee, D. J., S58

Lee, E., S66

Lee, F. N., 296, 819, S9, S58, S96

Lee, H. K., S40

Lee, I.-M., S58, S116

Lee, J., S58

Lee, K. J., S114

Lee, L., S58

Lee, M. H., S58

Lee, R. F., S8, S37

Lee, S. (Kans.), S135

Lee, S.-E. (Korea), S19

Lee, S. H. (N.D.), S58

Lee, S. W. (Calif.), S135

Lee, S.-W. (Korea), S59

Lee, W. C., S40

Lee, Y. H., S3, S51, S53, S59, S81

Lee, Y.-K., S73

Legard, D. E., 446

Legare, D., S10, S64

Legg, D. E., S152

Leifert, C., 351

Leininger, T. D., S59, S110

Leite, B., S44, S59

Lemay, A. V., S59

Lens culinaris, anthranose, races and resistance, 236

Lentini, Z., S135

Leonard, K. J., 505

Leong, S., S23

Leptographium wingfieldii, bark beetle association, in North America, S163

Leptosphaeria maculans

- on Brassica napus, major specific resistance genes, 578

- on canola, single gene resistance, S60

Lesage, M.-L., 345

Leskey, T. C., S142

Leslie, J. F., 520, S58

Lesnaw, J., 912

Lessing, F., S122

Less1, J. T., S59

Lester, D. G., 419

Leth, V., S75

Letourneau, Y., S159

Letter to the Editor

- phylogenetic coverage, genomic sequencing, 800

—-statistics, nonparametrics, factorials, 33

Lettuce

- downy mildew: fungicides, S29; model in Norway, S76; sporulation factors, 396

-Fusarium wilt: California, S154; resistance, S153

- mildew, cultivar resistance, S36

-phytoplasma, strain analysis, molecular, 842

-Sclerotinia drop, chemical and biological treatments, S67

- Sclerotinia, forecasting model, sclerotial germination, 268

Lettuce big-vein virus, Mirafiori lettuce virus comparison, diagnosis techniques, 470

Lettuce infectious yellows virus, whitefly transmission, molecular features, S75

Leung, H., S90, S135

Leverentz, B., S20

Levy, A., 826

Levy, L., 61, 868, S138

Levy, N. O., S59

Lewandowski, D. J., S3, S48

Lewellen, R. T., S62

Lewis, A., S22

Lewis, C. D., S60

Lewis, M. L., S74

Lewis, W. J., S48

Li, H. (Australia), S60

Li, H. F. (China), S29

Li, H. J. (Wash.), 932

Li, L., S135
Li, Q., S112

Li, R., S12, S60

Li, S., S60, S159

Li, W. (Ky.), S87

Li, W.-B. (Md.), S56, S60

Li, W.-X. (Calif.), S131

Li, X., S60, S160

Li, Y., 1031

Liang, D., S58

Liang, X. M., S29

Liao, C.-H., 76

Liew, E. C. Y., S61

Lilium speciosum, Botrytis resistance, S17

Lim, H. K., S59

Lim, H. S., S61

Lima bean, downy mildew, fungicide trials, S24

Lima, M. F., S61

Lin, C.-H., S61

Lin, H., S31, S61

Lin, S., S123

Lindera melissifolia, stem canker and dieback, severity in Mississippi, S110

Linder-Basso, D., S84

Linderman, R. G., S126

Lindow, S., S27, S75, S110, S121, S128

Linholm, K. M., S61

Lipp, C., S84

Lipps, P. E., 1342, S28, S72, S82, S102, S164

Lisianthus, Fusarium stem rot, aerial transmission by insects, $\mathrm{S} 27$

Liu, B., S62, S135

Liu, G.-F., S135

Liu, H., S49, S62, S111, S121

Liu, J. J., 1235

Liu, L., S159

Liu, Q., S62, S116

Liu, W. C., S160

Liu, Z. (Ohio), S156

Liu, Z. H. (N.D.), 1056, 1061

Llamas, S., 69

Lo, C.-T., 1031

Locke, J. C., S62

Loeza-Kuk, E., S35

Logiudice, N., S62

Lolium perenne, stem rust, phenology, 308

Loparco, D. P., S94

Loper, J. E., 1228, 1286

López, J., S143

Lorbeer, J. W., S94

Lori, G., 661

Loria, R., S48, S51, S106, S123

Lorito, M., S139

Lourenço, V., Jr., S63

Louws, F. J., 184, S10, S57, S63, S94, S137

Lozano, I., S135

Lu, G., S42

Lu, R., S131

Lu, S.-E., S63, S107

Lu, Y., S63, S94

Lu, Z.-X., S63

Lucas, J. A., S20, S31

Lucas, W. J., S117

Ludwig, G. C., S63

Ludwig, J. W., S1

Lundquist, J. E., S8, S64

Lung-Escarmant, B., 125

Luo, M., S64

Luo, Y., 326, S64, S155

Lupine, anthracnose, strobilurin fungicides, S164

Luster, D. G., 868, S12, S24, S64, S69, S141

Lutton, E., S69

Luvisi, D. A., 1136

Lynch, N. P., S63

Ma, J., S63

Ma, L., S122

Ma, Z., 326, S155

Mabagala, R. B., 593

MacDonald, J. D., S112

MacGuidwin, A., S78 
Machinandiarena, M., S64

MacKenzie, S. J., 446, S64

Mackey, B. E., S71

Macrosteles striifrons, onion yellows phytoplasma vector, 244

Madden, L. V., 33, 999, 1342, S72, S76, S82, S84, S137, S138, S164

Maddula, V. S. R. K., S64

Madisa, G., S65

Madsen, M., 551

Maffia, L. A., S21, S37, S63

Magarey, P. A., S50

Magarey, R. D., S44, S53, S65, S130

Magnaporthe spp.

-M. grisea: appressorium formation, gene expression profiling, 1032; genomic analysis, S122; manganese peroxidase-like genes, deletion, S103; on rice, avirulence and molecular characterization, $\mathrm{S} 111$; on rice, gene change and nitrogen starvation, appressoria, S26; on rice, molecular evolution of gene, S47; on rice, monogenic line durability, S52; on rice, partia resistance, ethylene induction, 819; on rice, phytoalexins for resistance, 177; on rice, $\mathrm{Pi}$ - $\mathrm{ta}$ resistance gene, USA, 296; on rice, proteomic analysis, S53; on rice, resistance gene $P i 7(t)$, sequence markers, 302; secretome, proteomic identification, S122; telomere association, pathogenic adaptation, S87; transcriptomes, analysis, S53

-M. oryzae, on Lolium spp., species-specific pathotypes, genetics, 454

-M. poae, on creeping bentgrass, North Carolina, S103

Mahaffee, W. F., 1116, 1156

Mahoney, N., S154

Mahrer, Y., 132

Main, C. E., S65, S130

Mair, J., S48

Maize (see also Corn)

-aflatoxin accumulation, stress-related protein, 938

-Aspergillus flavus on kernels, chitinase growth effect, 82

-Fusarium verticillioides, kernel infection, fumonisin, 88

- genomic analysis, reductases and plantpathogen interaction, S114

— gray leaf spot, preplant risk assessment, 1350; gray leaf spot, resistance, S125

- lipoxygenase genes, genomics, S75

-mycotoxins, chromatographic method, S55

— northern leaf blight, spatial diversity, eastern USA, 892

-Phaeosphaeria leaf spot, etiology in Brazil, S23

—smut, genes, S73

- southern leaf blight, race $\mathrm{O}$, resistance locus mapping, 862

-Trichoderma harzianum seed treatment, interaction with pathogens, 147

Maize fine streak virus, genome, sequence and analysis, $\mathrm{S} 103$

Maize mosaic virus, in planthopper vector tissues, confocal microscopy, S4

Maize streak virus, incidence in Nigeria, S101

Maloney, S. C., S93

Malvarez, G., S65

Malvick, D., S65, S158, S160

Manfio, G. P., S66

Manisterski, J., 94, 505, 569, 632

Manjunath, K. L., S8, S37, S90

Mann, K. L., S65

Manosalva, P., S65, S90, S135

Mansfield, M. A., S55

Mansour, M. F., S71

Manuscript preparation, author's guide, 7

Mao, Z. S., S43

Maples, H. W., S98, S168

Maragos, C. M., 251

Marais, L. J., S8
Marasas, W. F. O., S55

Marçais, B., 826

Marchoux, G., 345

Marco, Y., 289

Marek, S. M., S25

Marett, C. C., S73

Maris, P. C., 706

Markova, J., S125

Marois, J. J., S145

Maroon-Lango, C. J., S38

Marques, L., S9, S59, S66, S78

Martin, D. L., S170

Martin, E. M., 111

Martin, F. N. (Calif.), 621, 983, S66

Martin, F. (France), S133

Martin, G. B., S121

Martin, K. J., S83

Martin, M., S66, S95

Martin, R. (France), S47

Martin, R. A. (Calif.), 1145, S55, S66, S104, S130, S137

Martin, S. B., S22, S66, S81, S83

Martin-Duvall, T., S57

Martinez, C., S164

Martínez-Campos, A. R., S67

Martinez-Espinoza, A. D., S82, S145, S146

Martinez-Ochoa, N., S67, S146, S157

Martino, F. O., S11

Martyn, R., S27

Maruhenda, A., 470

Marvel, J. K., S142

Marvelli, R. A., S67

Matheron, M. E., S67, S88, S153

Mathew, F. M., S160

Mathews, D. M., 1337, S153

Mathews, S., 912

Mathur, S., S75, S155

Matías, C., S83

Matsumoto, N., 561

Matta, C., S140

Matveeva, E. V., S43, S67

Mavrodi, D., S67, S108

Mavrodi, O., S67

Mavrodieva, V., 61

Maxson-Stein, K. L., S67, S98, S168, S169

May, G., S119

Mayama, S., 454

Mayfield, J. L., S46

Mayton, H., S68

Mazzola, M., S20, S68, S125

Mbofung, G. Y., S68

McAlpin, C. E., S68

McBeath, J. H., S18, S151

McCallum, B. D., 432

McCormick, W. A., S15

McCreight, J. D., S153

McCuiston, J., S100

McDonald, B. A., 261, S126

McDonald, G. I., S38, S127

McDonald, K., S100

McDonald, T. R., S38

McDonald, V., S68, S125

McDowell, J. M., S107

McEvoy, J. L., 44

McFadden, A., S78

McGhee, G. C., S68

McGovern, R. J., S147, S169

McGrath, M. T., S69, S74, S165

McKay, K., S10

McKee, B., S68

McKenry, M. V., S151

McLain-Romero, J., S69

McMahon, M. B., S64, S69

McManus, P. S., 1164, 1172, S41

McMullen, M., S69, S169

McNally, D. J., 177

McPhee, K. E., S17

McSorley, R., S129

McSpadden Gardener, B. B., 1244, 1252, S37, S69

McWilliams, M., S35, S48
Medd, R. W., 805

Mednick, A., S132

Medrano, E. G., S69

Meeley, R., S75, S114

Mei, C., S70

Meinhardt, S. W., 1056, 1061

Meitl, A., S113

Meke, G., S89

Melaleuca alternifolia, oil for disease control, S150

Melampsora spp., evolution, molecular evidence, S126

-M. larici-populina, on hybrid poplar, resistance and factors, 1358

-M. medusae, pathosystem, genomics approach, S127

Melanin

-Ascochyta blight of chickpea, role, S132

- biosynthesis, genetics, S132

-Cryptococcus neoformans, role, S132

-mechanical value, S132

-rice blast, appressorial penetration, S132

Melcher, U., S47, S73, S115, S124

Melchior, G. L., S153

Melian, L., S102

Melidossian, H. M., S70

Meloidogyne spp.

-M. hapla, virulence genetics, S62

-M. incognita: Muscodor sp. effect, gas-producing, S117; suppression by cover crops, litter, and compost, Pratylenchus comparison, S28

Melon (see also Cantaloupe and Cucumus melo)

- Cucumber mosaic virus, Spain, 992

-Fusarium wilt, resistance to race 1.2, polygenic, 1331

— powdery mildew, quinoxyfen effect, California and Arizona, S88

Melon chlorotic leaf curl virus

-recombination with other begomoviruses, S43

-in Squash leaf curl virus clade, S150

Melouk, H. A., S18, S92

Melton, T. A., S100, S147, S169

Melzer, M. J., S154, 1031

Mendoza, A., S51

Menelas, B., S160

Meneses, R., S135

Meng, X., S70, S85

Meng, Y., S135, 1031

Menge, J. A., S68, S125

Menzies, J. G., 177, S165

Merhaut, D., S80

Mertely, J. C., S70

Messmer, M., 1036

Metheney, P. D., S85

Methylobacterium mesophilicum, on sweet orange, Xylella fastidiosa infection, PCR assay, S56

Mghalu, J. M., S103

Miao, H., S80

Michailides, T. J., 326, 1189, S26, S64, S70, S155

Microdochium nivale, on bentgrass, cultivar evaluation, S15

Mideros, S. X., S70

Miedaner, T., 520

Miklas, P. N., 320, S153

Mikuszewski, A. L., S159

Mila, A. L., 102, 1027, S70

Miles, M. R., S124

Milgroom, M. G., 228, 544, S7

Miller, G., S102

Miller, J. S., S40, S44, S71, S85

Miller, P. K., S45

Miller, S. A., 842, S74

Miller, S. L., S76

Miller, S. S., S45

Miller, T., S8

Miller, W. A., S71

Milles, M. R., S29

Millett, B. P., S71

Mills, K., S43

Milus, E. A., S95 
Milyutina, I. A., S67

Ming, R., S154

Mint, new viruses, detection and analysis, $\mathrm{S} 104$

Mirafiori lettuce virus, on lettuce, molecular diagnosis techniques, 470

Miranda, J. G., S71

Mirkov, T. E., S132

Mirusso, J., S16

Mitchell, F., S170

Mitchell, T., S22, S26, S107, S122, S135, 1032

Mitkowski, N. A., S47

Miyasaka, A., S44

Miyata, S., 244, 683

Mizubuti, E. S. G., S21, S37, S63

Mkandawire, A. B. C., 593

Mlambo, F., S89

Mlikota Gabler, F., S71

Mmbaga, M. T., S72, S95

Mock, R. G., S60

Model

—disease epidemics, spatial hierarchy, S110

-disease forecasting, statistics, symposium, 1007

- epidemiological: nested structure, cover photo, August; simulation, spatial hierarchy, 883

- gene interaction, diploid host and haploid pathogen, S113

-leaf wetness duration: estimation, Costa Rica, S52; fuzzy logic system, S53

- peach rust, lesion development and disease progression, analyses, 52

- Pyrenophora semeniperda, climate and geographic range, 805

- rhizomania, sugar beet, control strategies in UK, 209

- Sclerotinia sclerotiorum, lettuce, predicting model for sclerotial germination, 268

- sibling fungal plant pathogens, host specialization, evolution, 789

- soybean, Sclerotinia stem rot, regression, 102

-take-all of wheat, host growth and epidemiology, 535

Mohan, S. K., S153

Mohr, P. G., S72

Moldenhauer, K. A. K., 296

Molina, J., S132

Molineros, J. E., S33, S72

Molyneux, R., S154

Momol, M. T., S46

Mondal, S. N., 978, S72

Money, N. P., S132

Monfort, W. S., S72, S169

Monilinia spp.

-M. fructicola: on prune, latent infection, S64; on stone fruit, fludioxonil sensitivity, S78; on stone fruit, fungicide resistance, S155; on stone fruit, transformation methods, S58

-M. vaccinii-corymbosi, ascospore discharge, temperature effect, $\mathrm{S} 92$

Monosporascus cannonballus

- growth and reproduction, melanin biosynthesis inhibitors, S29

-on melon, fumigation, S154

- osmotic water potential, growth and reproduction effect, $\mathrm{S} 29$

Montes, N., S146

Montez-Ellis, M., S160

Moore, G. A., S29

Moore, J. A., S38

Moore, K. G., 82

Moore, M. K., S18

Moorman, G. W., S33, S55

Mora-Aguilera, G., S35

Morales, E., S98

Morales, G., S72

Morea, M., 484

Moreira, A. J., S10, S73

Morello, J. E., S51

Moreno, P., S130

Moretti, A., 345

Morgan, D. P., 1189
Morgan, E. J., S11

Morgan-Collins, D. J., S20

Morgan-Jones, G., S80

Mori, N., 454

Morin, C., 1323

Morissette, D. C., S165

Morrall, R. A. A., 236

Morris, N. C., S12

Morse, A., S133

Mortimer, M. W., S93

Morton, A. N., S107

Moskowits, Y., S131

Mosquera, G., S136

Moyer, J. W., S1, S153

Mrema, F. A., S72

Mucor spp., on guava, new Hawaiian strain, S153

Muehlbauer, F. J., S17, S18, S132

Mueller, D. S., S22, S40, S41, S73, S111, S145

Mueller, J. D., S102

Mueller, J. P., S88

Mueller, P., S122

Mueller, S. M., S31

Muhinyuza, J. B., S54, S160

Müller, M. L., S74

Mullinix, B. G., S147

Mullins, C. E., 351

Mullis, S. W., S67

Mulrooney, R. P., S24

Mundell, J. N., S73

Munkvold, G. P., 1350

Muñoz, G., 875

Munyaneza, J. E., S58

Muralitharan, M. S., S23

Murillo-Williams, A., S10

Murphy, J. A., S164

Murray, T. D., 932

Musetti, R., 203

Musson, G., S31, S146

Mutaqin, K., S73

Mutlu, N., S73

Mycoparasitism, endochitinase gene, RT-PCR analysis, S165

Mycosphaerella spp.

- M. citri: on citrus, mating and pseudothecial development, 978; greasy spot, factors, S72; pseudothecia, mature and barren, cover photo, September

-M. graminicola: QoI resistance, evolution, S31; on wheat, mitochondrial genome, natural section, 261; on wheat, partial resistance, 497; on wheat, phylogeographical history, S126; on wheat, quantification, S2

Mycotoxin

-aflatoxin: Aspergillus ear rot of corn, inbreds, 1107; genes, cDNA microarray, S86; maize, stress-related protein, 938; resistance-associated protein in maize, $\mathrm{S} 18$

-Aspergillus flavus on maize kernels, 82

-deoxynivalenol: barley and Fusarium head blight, accumulation, 1145; Fusarium head blight of barley, host effect, 766

-fumonisin: biosynthesis and microenvionment, S120; biosynthetic pathway by deletion analysis, S120; in corn grain, genetic resistance, S120; Fusarium ear and kernel rot, corn, 251; Fusarium verticillioides on maize, kernels, 88; risk assessment and emerging issues, S120

-maize, genomics approach, S120

-trichothecene, type-A from Fusarium, analysis, S117

Myers, J. R., S19

Myers, R. A., S146

Mysore, K. S., S49

Myung, I.-S., S73

Myxococcus spp., detection with PCR, S83

Myzus persicae, Plum pox virus, North America, 868

Nada, S. E., S115

Nadal, M., S73
Nadiga, M., S74

Naeve, S., S159

Nagai, C., S154

Nagashima, K., 813

Nagatsuka, T., 813

Nagendran, S., S74

Naidu, R. A., S74

Nakabonge, G., S74

Nakagawa, A., S101

Nakagawa, S., 454

Nakaho, K., S101

Nakamura, H., 561

Nakayashiki, H., 454

Nakkeeran, S., S115

Nam, K.-W., S73

Nam, M. H., S113

Namba, S., 244, 683

Nance, J., S16

Narasimhan, B., S111

Narisawa, K., 412

Nasturtium officinale, phytoplasma disease, in Hawaii, S9

National Soybean Pathogen Collection Center, pathogen conservation system, S60

Natwick, E., S37

Nault, L. R., 842

Nava-Diaz, C., S74

Navarro, J. A., 470

Navas-Cortés, J. A., 946

Navi, S. S., S74, S146, 796

Neale, D. B., S133

Neate, S. M., S58

Nectria haematococca, rhizosphere colonization, chromosome role, $\mathrm{S} 109$

Nelson, C. D., S133

Nelson, D., 1032

Nelson, R., S20, S51

Nematodes

- ecosystem management, nutrient cycling, plant health, S129

- golf course greens, population factors in New England, S47

-oat, flavone as defense, 1207

- organic and conventional farming system, S129

-root-knot, root cell proliferation, S42

-in soil ecosystems, diversity, S128

— soil nutrient cycling, role, S129

- suppressive soil, decoding nature of, S129

- vectors for three plant viruses, detection, S55

Nemchenko, A. M., S75

Nemchinov, L. G., 912

Neotiphodium coenophialum, on tall fescue, endophyte, nematode host, S170

Nerad, T., S163

Nesmith, W. C., 1178

Newman, K. L., S75

Newman, M. A., S75

Newton, A., S31

$\mathrm{Ng}, \mathrm{J} ., \mathrm{S} 75$

Ngo, X. T., S75

Nguefack, J., S75

Ngugi, H. K., S75

Nguvulu, C., S89

Nguyen, K.-P., S6

Ni, H. F., S76

Niblack, T., S60

Nicotiana spp. (see also Tobacco): virus resistance genes, introgression, S110

$-N$. benthamiana, Peanut stunt virus, ribbon-like inclusions, 722

$-N$. obtusifolia, downy mildew, necrotic lesion resistance, 1178

Nie, X., 1368

Nielsen, C. J., S76, S153

Nikolaeva, E. V., S67

Nishigawa, H., 244, 683

Nishijima, K. A., S153

Nishijima, W. T., S153

Nita, M., S70, S76

Nitric oxide, detection in plants, electron spin 
resonance, 402

Nitta, H., 561

Nitzan, N., S76

Niu, X. F., S160

Nolte, P., S85

Nomura, K., 730

Nordskog, B., S76

Norelli, J. L., S76, S142

Norman, D. J., S77

Nosanchuk, J., S132

Nunez, A., S64, S69

Nunez, J., S70

Nutter, F. W., Jr., S10, S28, S73, S77, S130, S158, S160

Nyczepir, A. P., S77

Oak (see also Quercus spp.)

-bacterial leaf scorch, economics in New Jersey, S36

- sudden death, nursery survey in Texas, S5

-wilt: control research, S65; Texas project in 16th year, S13

Oat (see also Avena sterilis)

- crown rust: virulence pattern, USA and Israel, 505

-flavone, nematode defense, 1207

Oberle, C. S., 419, S110

Oberoi, K., S156

Obituaries

-T. E. Freeman, 220

-Robert W. Fulton, 916

-Glenn Snow, 124

O'Brien, D., S136

Ocamb, C. M., S85

Occhialini, A., S121

Ochiai, H., 478

Ochiai, N., S125

Ochoa, D. L., S72

Ochoa-Corona, F. M., S57

Ochoa-Martínez, D., S35

O’Donnell, K., S117, S122

Odvody, G., S146

Oelke, L. M., S77

Oemichen, B., S78

Oh, Y., S26, S122, 1032

Ohshima, K., 730

Oikawa, Y., 561

Ojiambo, P. S., 1022, S77

Oke, K. E., S101

Okori, P., 743

Oku, T., 478

Okubara, P. A., S77

Olanya, O. M., S77

Olatinwo, R. O., S78

Olaya, G., S78

Oleas, A. R., S28

Olive

- cane dieback, in Iran, S91

- disease survey, Argentina, S83

-knot formation, $h r p$-dependence, 484

Olive, J. W., S37

Olivier, A. R., S49

Olivier, J., 289

Olpidium brassicae, lettuce virus vector, diagnosis techniques, 470

Olsen, M. W., S54, S66, S154

Olsen, N., S71

Olson, B. D., S78

Olson, B. R., S106, S170

Olson, M. E., S9, S59, S66, S78

Olson, S. M., S46

Omer, M., S78

Onion

-bacterial blight, spatial and temporal analyses, 138

-bacterial leaf blight and bulb rot, in Peru, S145

-neck rot, sclerotial survival, in Australia, S18

— phytoplasma, insect transmission, analysis, 244

-Xanthomonas leaf blight: copper bactericides, acibenzolar, S34; management strategies, S56; polyphasic characterization, 184

Onoue, M., 561

Ophiomyia simplex, on asparagus, Fusarium crown and root rot relation, $\mathrm{S} 161$

Ophiosphaerella herpotricha, on bermudagrass, temperature effect, $\mathrm{S} 107$

Ophiostoma novo-ulmi

-nuclear genome, analysis, S8

- satellite RNA, mitovirus 3a, 917

Orbach, M. J., S135

Ordoñez, M. E., 154, S79

Ordovás, J., 1094

Organic farming

— crop protection materials, national list, S137

- disease research in California, S136

— management and plant disease, S136

- projects and funding opportunities, S137

- systems and plant pathology, S137

-USDA/ARS survey, S150

Oriolani, E., S83

Orlando, R., S122

Orlova, I. A., S35

Ornamentals

—defense regulation, SGT1 genes, S115

-disease susceptibility, nitrogen, potassium, and silicon effects, S62

-tymovirus, California, S153

Orr, K. A., 1383, S79

Osaki, H., 561

Osborne, L. E., S72, S79

Oshima, K., 244, 683

Osterbauer, N., S35, S48

Osue, J., 454

Otaye, O. D., S79

Otero, L., S83

Otrosina, W. J., S79, S107

Ottaviani, M.-P., 544

Oudemans, P. V., S25, S84, S142

Ouimette, D., S78, S79

Owen, J., S113

Padgett, G. B., S146

Padilla, A., S69

Paecilomyces spp

- $P$. lilacinus, biocontrol, biopesticide risk assessment, S51

- polymyxa, on ginseng and chili pepper, starch hydrolysis, S46

Page-Dumroese, D. S., S88

Pagliaccia, D., S80

Pahalawatta, V., S80

Pair, S., S170

Palanivel, C., S35

Palencia, E. R., S80

Pallas, V., 470

Palle, S. R., S80

Palmateer, A. J., S80

Palukaitis, P., S58

Pan, H., S26, 1032

Pan, Q., 515

Pan, Y.-B., S36

Pan, Z., S80, S84

Panella, L., S24

Pangga, I. B., 221

Pantoea spp.

- P. agglomerans: antibiotics from, inactivation by Pseudomonas fluorescens; on cotton, seed rot in South Carolina, S69; on cranberry, galls, cover photo, November; on cranberry, stem gall, anatomy, 1172

- P. stewartii: on corn, biofilm, genes involved, $\mathrm{S} 41$; on corn, spatio-temporal analysis, in Mexico, S72; secretome analysis, S103

Papaver somniferum, biotechnological control method, S35

Papaya, yellow crinkle, survival in Australia, S28

Papaya ringspot virus, coat protein, on transgenic papaya, $\mathrm{S} 151$

Pappu, H. R., S81

Pardes, E., 632
Parisi, L., 370

Park, E. W., 970, 1295, S52

Park, H.-G., 1295

Park, J. J., S52

Park, J. Y., S81

Park, M. S., S81

Park, S.-Y., S19, S51

Parke, J. L., S60, S81

Parker, P. E., S9, S81

Parker, S. R., S81

Parkes, S. L., 1129

Parkhill, J., S123

Parks, P. S., S18

Parrella, G., 345

Partridge, D. E., S82

Partridge, J. E., S10, S30

Pasken, R., S80

Pastor-Corrales, M. A., S82, S124

Pasura, A., S160

Pataky, J. K., 251, S54, S120

Patel, N., S82

Pathogen detection

- geraniums, Ralstonia, case study, S138

-new tools, S130

—-sample strategies, S137

— sampling systems, S138

- technology innovations, in seed, S137

- viruses and stock programs, ornamentals, S138

- viruses and vectors in small fruits, S137

Pathogens

- emerging: GPS and GIS technologies, mapping, S130; mitigating effects, S130

-enteric, postharvest processing and storage practice, S128

- human, survival on plants, S128

- new and emerging, role of NPDN, S129

-weather-based simulations, S130

Pathosystem

—endemism, phylogeographical history, S127

- tropical, spore dispersal, rainfall, S92

Patiño, B., S64

Patte, C. P., 490

Paul, P. A., 1342, 1350, S82

Paulitz, T. C., S77, S82, S94

Paulus, A. O., S151

Pavich, S., S126

Paya, A. R., S163

Payne, G. A., 82, 88, S28, S86, S122

Payton, M., S170

Pea

— promoter gene DRR206, resistance, 651

- Sclerotinia sclerotiorum, populations in Pacific Northwest, S47

Peach

-Mesocriconema xenoplax, nonchemical control, $\mathrm{S} 77$

-Plum pox virus, strain M, roguing in France, 1390

—rust, lesion development, analyses, 52

- rusty spot, integrated management, S165

- Sharka disease, roguing in France, S23

Peacock, C. H., S58

Peanut

-aflatoxin accumulation, postharvest, S18

-aflatoxin tolerance and susceptibility, metabolite comparison, $\mathrm{S} 48$

- disease risk index, fungi, S50

—early leaf spot: fungicides, delayed application, S145; herbicide and crop residue effect on epidemic, S143; integrated management, S168

-foliar and soilborne diseases: fungicide, S146; fungicide programs, S170

_ genomics, EST-microarray analysis, S64

-leaf spot: advisory program, evaluation, S13; suppression by tillage, genotypes, and fungicides, S145

-microclimate, seeding rate and row pattern, S147

-rust, breeding lines and tillage, S168

- strip-till effect, cover crops and disease management, S13 
Peanut mottle virus, Peanut stripe virus comparison, detection with grid RT-PCR, S34

Peanut stunt virus, on Nicotiana benthamiana, ribbon-like inclusions, 722

Pear

- gray and blue molds, postharvest fungicides, S149

- scab, multiple defense response, induced resistance, 604

Pearce, M., S82, S146

Pecan, scab:

-fungicide programs, S167

- propiconazole sensitivity, S99

Pedersen, J. F., S32

Pedersen, W. L., S12

Peek, D. R., S47

Peeters, N., S121

Peever, T. L., S24, S27, S41, S127

Pei, M. H., S126

Pekarek, R. A., S83

Pelter, G. Q., S26

Peltier, A. J., S161

Peng, J.-L., 1048

Peng, S., 672

Penicillium spp., on apple and citrus fruit, acidification and virulence relation, 44

$-P$. digitatum: azoxystrobin, fludioxonil, and pyrimethanil, sensitivity, S49; on citrus, airsampling method, S97; on citrus, Verticillium lecanii, chitosan, 693; on citrus, wounded fruits, cover photo, July

Pennisetum glaucum

—-fungi and mycotoxins, S48

— grain mold, germplasm accessions, 796

Pennisetum mosaic virus, molecular variation, S29

Pepper (see also Capsicum annuum)

-bacterial spot, management in Oklahoma, S168

-famoxadone and cymoxanil for, management, S66

-harpin protein treatment, resistance induced, S56

-major resistance genes, systemic acquired resistance, 1376

Pepper, A. F., S83

Pepper veinal mottle virus, on Datura stramonium, Nigeria, S101

Pérarnaud, V., 826

Perchepied, L., 1331

Percich, J., S144

Peres, N. A. R., S3, S64, S70, S83, S94

Perez, B. A., S83

Perez, E. A., S154

Perez-Hernandez, O., S83

Perna, N. T., S20, S83, S95

Peronospora spp.

- P. antirrhini, on snapdragon, conidial concentrations, $\mathrm{S} 13$

$-P$. parasitica, resistance pathway, genetic dissection, $\mathrm{S} 107$

- P. tabacina, on Nicotiana obtusifolia, necrotic lesion resistance, 1178

Perry, K. L., S163

Pesticide residues, detection using electronic aroma, S110

Pest management, rice, priorities in tropical Asia, 672

Pest risk analyses, risk ratings, USDA, S59

Pest risk assessment, teaching, case study in Iowa, S10

Peter, M., S133

Peters, D., 706, S134

Peters, J., S105

Petersen, J. C., S154

Peterson, D. L., S45

Peterson, P. D., S22, S66, S83

Peterson, S. A., S84

Petrovic, N., S84

Petzoldt, C. H., S1

Petzoldt, R., 147
Pfender, W. F., 308, 999, S84

Pfirrmann, J., S45

Phaeomoniella chlamydospora, on grape cordons, spore release in California, S28

Phaeosphaeria spp., on cereal, glyceraldehyde-3phosphate dehydrogenase genes, S105

$-P$. nodorum, on winter wheat, telemorph frequency in North Carolina, S21

Phakospora pachyrhizi

-protein identification, mass spectrometry, S69

- on soybean, sequence tags and stages, S85

Phaneendra, C., S35

Phaseolus vulgaris (see also Bean)

-anthracnose: cultivar resistance, S158; resistance sources from Brazil, S162

-Beet curly top virus, Bct gene for resistance, mapping, 320

- common bacterial blight, genetic diversity and coevolution, 593

- diseases in North Dakota, S39

- pod rot, prevalence in Arkansas and Missouri, S101

—rust: resistance in Mozambique, S47; resistant cultivar, S107

-seedling diseases, S-metolachlor treatment, S167

Phellinus weirii, on Douglas-fir, gene cloning, thaumatin-like protein, 1235

Phelps, K., 268 Phialophora sp., on grape, California, S151

Phibbs, A., S84

Philion, V., S84, S165

Phillips, C. T., S96

Phillips, D., S60

Phillips, J. L., S1, S95

Phoma spp.

- P. medicaginis, on alfalfa, transformation by Agrobacterium, S25

- . sclerotioides, on alfalfa, 14 isolates tested, $\mathrm{S} 152$

Phylloplane, yeast:

-bentgrass and tall fescue effects, irrigation, S4

- geranium disease control, fungicides, 196

Phyllosphere, epiphytic bacteria, biosensors, S17

Phyllosticta telopeae, on waratah, populations and ecosystems, S84

Phylogeny, cytochrome P450s, pathogenic and nonpathogenic fungi, 1032

Phytoalexins, rice blast, silicon effect, 177

Phytophthora spp.: on avocado and citrus, soil microorganisms for management, S125;

-in hardwood forest, Appalachian Mountains, USA, S118; irrigation regimes and disease, S153; molecular identification, RFLP, 983; phylogeny, mitochondrial DNA, S66, on taro, in Hawaii, S155; zoospore movement and infection in water, $\mathrm{S} 79$

-P. cactorum, FAME profile analysis, S39

-P. capsici: on chile, soil water effect, $\mathrm{S} 91$; on cucurbit, inoculum from irrigation water, S157; mefenoxam sensitivity and mating type, overwintering, S158; on pepper, fertility amendments and tillage, S62; on pepper, hydroponic culture, S76; sensitivity to mefenoxam, dimethomorph, zoxamide, and cymoxanil, S50; soil solarization, Florida, S144; on vegetables, fungicides, S5; vegetable seedling resistance, irradiation, S44

-P. cinnamomi: on avocado, resistance, S85; on oak, winter temperature mapping, France, 826 on ornamentals and Fraser fir, dimethomorph and phosphites for, S167

-P. erythroseptica: mefenoxam resistance, inheritance, S156; mefenoxam-resistant isolates, Idaho, S85

-P. infestans: on Arabidopsis, nonhost resistance, S159; avirulence genes, comparative genomics, S156; chemical control, Argentina, S4; extracellular protease inhibitors, counterdefense, S136; GIP gene family, molecular cloning, S24; glucanase inhibitor proteins, S136; meta- laxyl response, isolates, S5; population history, DNA sequence, S35; on potato, fungicides in Ecuador, S101; on potato, genetic diversity, in Ecuador, 154; on potato, genotype and storage temperature, S2; on potato, inhibitor proteins, 1031; sporangium-specific genes, function, S53; spore development, signal transduction, S48; survival below $3^{\circ} \mathrm{C}, \mathrm{S} 157$; survival in surface water, 380; zoosporogenesis, temperature-dependent gene expression, S101

- . nicotianae, on periwinkle, biopesticides, inoculants, biorational products, S113

- . parasitica: races, variety rotation effect, S169; suppression in compost, swine waste, 780

- P. ramorum: American and European populations, diagnosis, 613; on conifer shoots, S16; on Douglas-fir, fungicides, S16; in forest and nurseries, isolate virulence in Oregon, $\mathrm{S} 81$; in forests, eradication strategy in Oregon, S35; on oak, Oklahoma survey, S106; on oak and other species, detection in California forest, PCR assay, 1075; in Oregon forests, monitoring, S48; on ornamentals, North Carolina, S7; persistence in plants and soil, S95; quantification, real-time PCR, S40; recovery from plant material, molecular detection, 621

-P. sojae: races, comparison, $\mathrm{S} 160$; on soybean, defense genes in two cultivars, S21; on soybean, disease susceptibility genes, S70; on soybean, management in Illinois, S65; on soybean, partial resistance, $\mathrm{S} 159$

Phytoplasma

-on apple, recovery in trees, ultrastructure, 203

- genomics, structural and functional, S123

- on lettuce, strain analysis, molecular, 842

-onion, insect transmission, analysis, 244

- phytoplasma: phylogenetic analysis, on concatenated proteins, S116; potato purple top and potato witches'-broom, relation in USA, S58; SecA membrane protein, antibody, 683

Phytotoxin, thaxtomin A, auxin amelioration, S102

Piche, L. M., 1368

Pierson, E. A., S64

Pierson, L. S., III, S64

Pieterse, C. M. J., S108

Pietrowicz, J., S80

Pilet-Nayel, M. L., 578

Pinaria, A., S61

Pinchback, M., S8

Pine

-anatomical response to stress or infection, S107

—defense response, biochemistry, S133

-loblolly: decline, resin duct necrosis, S107; fusiform rust, resistance, S170; genetic architecture of interactions, S133

-ponderosa: Armillaria root disease, fire effect, S8; black-stain root disease, inoculation, S79

-white, blister rust, gene distribution, western North America, 751

Pineapple, mealybug wilt:

- diversity, 1031

-transgenic plants, S154

Pinkerton, J. N., S55

Pinnow, D. L., S34

Pino Del Carpio, D., S84

Pinson, S. R. M., S47

Pinus spp.

- P. contorta, Gremmeniella abietina, resistance to European race, S164

- P. pinaster, Armillaria ostoyae, primary and secondary infection, dynamics, 125

Pistacia spp.

- P. atlantica, Verticillium wilt, rootstock effects, 388

-P. vera, Botryosphaeria dothidea: conidial dispersal, rain effect, 1189; population structure, California orchard, 326

Pitchay, D., S62 
Pitman, R., S168

Pitrat, M., 1331

Pittman, R. N., S34, S145

Pivonia, S., S80, S83, S84

Plant health, border cells, specific gene expression, S109

Plant medicine, program, University of Florida, S147

Plasmodiophora brassicae, genetic variation, analysis, Korea, S40

Plasmopara viticola, grape, epidemics, S50

Plattner, R. D., S120

Plectosporium tabacinum, on snap bean, new disease in New York and Maryland, S26

Ploetz, R. C., S85

Plum pox virus

—aphid vectors, North America, 868

- detection and quantification, S93

-host range, aphid transmission, S24

—on peach, strain M, roguing in France, 1390

- stone fruit survey in New York, S97

Pniewski, T., S55

Poa trivialis, rapid blight, fungicides, S154

Podosphaera spp.

- P. clandestina, on sweet cherry, biology, $\mathrm{S} 13$

-P. macularis, on hop, spatial pattern analysis,

Pacific Northwest, sampling, 1116

-P. xanthii, on cucurbit, fungicide resistance, S69

Pogany, J., 69

Pogrebnyak, N., S55, S85

Polek, M., S85

Pollution, air, phyllosphere-mediated removal, S91

Polston, J. E., 490

Polygalacturonase-inhibiting protein, cantaloupe fruit, 337

Polymyxa graminis, soilborne virus vector, wheat, 527

Pomegranate, wilt, biocontrol, S43

Pomella, A. W., S25

Pond, E., S68

Poplar, leaf rust, quantitative resistance, 1358

Poplawsky, A. R., S85

Porchas, M., S67, S153

Porter, L. D., 380, S85

Porter, P., S10

Posada-Buitrago, M. L., S85

- ethanol and temperature effect on spores, S71

Postharvest pathology

- antagonist for fruit wounds, bioreporter system, S46

-Botrytis cinerea: on grape, biocontrol, 924; on kiwifruit, biocontrol with grape volatiles, 1280

-citrus green mold, biocontrol, chitosan comparison, 693

—ethanol and temperature effect on spores, S71

-Penicillium spp. on apple and citrus fruit, acidification and virulence relation, 44

Postman, J. D., S104

Postnikova, E., S85, S88

Potato (see also Solanum spp.)

-black dot, azoxystrobin and inoculum source, S76

—brown rot: bacteria, Russian Federation, S67; virulence and temperature relation of pathogen, 463

—certified tubers, fungal diseases, $\mathrm{S} 90$

- common scab: cultivar resistance, S110; nitric oxide and phytotoxin, S106; resistance induced, S158; Streptomyces effect, S108

- cultivars, endomycorrhizal colonization, transgenic, S103

—early dying, nematode and Verticillium wilt relation, $\mathrm{S} 78$

-late blight: forecasting, logistic regression analysis, S40; genetic diversity, host specificity, Ecuador, 154; genotype diversity and disease, S77; pathogen survival in surface water, 380; $\mathrm{R}$ gene, tissue-specific, S71; resistance and fungicide application, management, S160; resistance and fungicide management, S54; spatial pattern analysis, aerial photography, S152; temperature, photoperiod, phenolic deposition, S161; tuber resistance, major R-gene, S68

-Phytophthora infestans, interaction, S87

— pink rot, fungicide evaluation, S78

- pink rot and Pythium leak, phosphorous acid effect, S44

- postharvest late blight, biocontrol in storage, S96

-Rhizoctonia disease: microbial antagonists and ryegrass rotation, S163; Moncut fungicide, S153

- Rhizoctonia solani, anastomosis groups, detection device, 280

- silver scurf, postharvest fungicides and disinfestants, S71

—smut, molecular analysis, 875

- stem rot, diversity and outcrossing, Washington, 737

— virus survey in New York and Maine, S163

-viruses and weed hosts, epidemiology, S154

Potato leafroll virus

- coat protein, virion stability and aphid transmission, S58

- strain specificity and replicase gene, S154

Potato virus $X$, vector for Peanut stunt virus coat protein, 722

Potato virus $Y$; transgenes and RNA silencing, S97; diversity among isolates, 1368

Potebniamyces pyri

- conidial germination, factors, S62

-on pear: growth and sporulation factors, S112; inoculum availability and survival, S112

Poussier, S., S136

Powell, C. A., S86

Powelson, M., S125

Powers, K., S65

Powers, L. B., S152

Poza-Carrión, C., S128

Prabakar, K., S151

Pradhanang, P. M., S46

Prasadbabu, G., S35

Pratt, P. D., S87

Pratt, R. G., S86

Presting, G., S65

Price, M. S., 82, S86, S122

Proctor, R. H., S120

Proffer, T. J., S86

Prom, L. K., S146

Prunus pp.

— cherry foveaviruses, RT-PCR assay, S60

-replant disease, fallow and rotation effect, S11

Prusky, D., 44

Pruvost, O., 138

Pryor, B. M., S42, S68

Pseudomonas spp.: bacteriocin activity, S67; hydroponically grown plants, population enhancement, S80

$-P$. aureofaciens, adhesion/biofilm formation, phenazines, S64

$-P$. chlororaphis, multiple pathogen control, S115

-P. fluorescens: extracellular protease, antibiotic inactivation, 1228; long-term survival, in soil, S4; on pear and apple, iron bioavailability, 1286; Pythium damping-off on sugar beet suppressed by, temperature, 351; in rhizosphere, genotype competition, S24; take-all disease relation, suppression, S105; on wheat and pea, root colonization, S67; in wheat and pea rhizospheres, transgenic, S8

$-P$. putida: biofilms and stress tolerance, lowwater habitat, S15; on corn and velvetleaf, electron microscopy, S31; survival, cell envelope constituents, S105

$-P$. syringae: alginate gene expression, $\mathrm{S} 152$; on Arabidopsis, systemic resistance, induction, S108; on Brassica spp., coronatine effect in pathogenesis, S27; coronatine, regulation, S169; on crucifer, cover crop mixture, S150; on crucifers, host range, S12; diverse plant interaction, S121; innate immunity, suppressors, S136; model organism, S121; on olive, knot formation, $h r p$-dependent, 484; osmosensitivity and osmoprotection in strains, S17; phytotoxin, SalA regulon, S63; programmed cell death, S110; quorum sensing, virulence and epiphytic fitness, S27; secretion systems and comparative genomics, S121; on sweet cherry, budsticks in New York, S104; on sweet cherry, epidemic in Michigan, S87; on tomato, antibacterial metabolite production, regulators, S40; on tomato, coronatine regulation, S97; on tomato, functional genomics, gene-specific insertion mutants, S16; on tomato, screening method, S108; on tomato and Arabidopsis, HrpA mutants, S59

Pseudotsuga menziesii, Phellinus weirii, gene cloning, thaumatin-like protein, 1235

Psidium guajava

-Myrothecium verrucaria in nematode interaction, in Mexico, S143

-nematodes on, activity in Mexico, S143

Puccinia spp.: on barley, substomatal vesicles, cover photo, January; on cereals and grasses, detection using real-time PCR, S6; on ornamentals and sweet corn, light effect on spore germination, S73

$-P$. allii: on garlic and chives, DNA sequence analysis, 569; teliospore germination, cover photo, June

-P. coronata: on barley, gene mapping, 858; on wild oat, virulence pattern in Israel, USA comparison, 505

$-P$. graminis: on perennial ryegrass, phenology, 308 ; on ryegrass, fungicide and plant spread, S84; on ryegrass, secondary spread, cover photo, March

$-P$. hemerocallidis, urediniospore production, fungicide spray, S111

$-P$. jaceae, yellow starthistle control, California, $\mathrm{S} 12$

- P. lagenophorae, biocontrol agent, S142

$-P$. recondita, on cereal and grasses, taxonomy, $\mathrm{S} 125$

- $P$. sorghi, on sweet corn, epidemic source in New York, S95

$-P$. striiformis: epidemics and races in USA in 2003, S18; on wheat, temperature effect on aggressiveness, S95; on wheat and barley, resistance genes, inappropriate formae speciales, S80

$-P$. thlaspeos, on Isatis tinctoria, biocontrol agent, inoculum production, S155

-P. triticina: on Aegilops speltoides, new forma specialis, 94; on durum wheat, worldwide collections, S79; on wheat, genetic variation and virulence, 632; on wheat, management and mixtures, 961; on wheat, quantitative trait locus, tagging for resistance, 1036; on wheat, uredospore production, nitrogen effect, 712

Puchalski, B., S63

Pueraria lobata, soybean rust role in USA, S83

Pumpkin, powdery mildew, milk as foliar spray, S164

Punja, Z. K., S86

Pusey, P. L., 901, S86

Pyrenophora spp.

-P. semeniperda, geographic range, 805

$-P$. tritici-repentis: races, Czech Republic and Poland, S3; on wheat, distribution in Ohio, S28; on wheat, management and mixtures, 961

Pyricularia grisea, on rice:

- gene on chromosome 1,515

- molecular characterization, Arkansas, S9

Pythiogeton spp., on cypress and English ivy, North Carolina, S95

Pythium spp.: on bermudagrass, golf course putting greens, S81; on cereals, PCR identification in Washington, S94; greenhouse crops, damping-off and fungicide dose, S33; identi- 
fication, molecular fingerprint, S55; ornamental nursery, irrigation, S54; survey in Taiwan, S41

-P. christmatum, from Fraser fir, corn Pythium comparison, $\mathrm{S} 1$

$-P$. dissotocum, in nursery irrigation water fungicide resistance and pathogenic fitness, $\mathrm{S} 14$

$-P$. pseudointermedium, from corn, Pythium from Fraser fir comparison, $\mathrm{S} 1$

-P. ultimum: on maize, Trichoderma harzianum effect, 147; seedling damping-off suppressed by, compost tea, 1156; on sugar beet, dampingoff suppressed by bacteria, soil temperature, 351

Qi, M., S70

Qi, W., S161

Qi, Y., S20

Qin, Q. M., S86

Qiu, W., S14

Qu, S.-H., S135

Quebedeaux, J. P., S169

Quercus spp. (see also Oak)

-canker, winter injury mapping, France, 826

Quiñones, B., S27

Quiot, J.-B., 1390, S23

Ra, J. B., S45, S113

Raaijmakers, J. M., S125

Rabedeaux, P. F., S161

Raccah, B., S134

Radewald, K. C., S154

Rahman, M., S86

Rai, M., S132

Rains, G. C., S48

Ralstonia solanacearum

- biovar 2, virulence and temperature relation, 463

-colonization proteins required, $\mathrm{S} 121$

- genetic diversity and physiology, S121

- mutations, extracellular enzymes, S62

- pathogenicity determinants and genomics, S121

-on tomato, lipopolysaccharide and virulence, S49

—on Zingiberaceae, new race, Japan, S104

Ramadugu, C., S87

Ramarathnam, R., S115

Ramularia crupinae, biocontrol agent, S142

Rascon, J., S22

Rasmussen, J. B., 1056, 1061, S97, S107

Raspberry, winter survival and disease control, S161

Rathayibacter rathayi, on grasses and cereals, in Oregon and Maryland, S85

Rauscher, G., S68

Rayamajhi, M. B., S87

Rea, W., S146

Recalcitrant double-stranded RNA viral template, cloning method, $\mathrm{S} 104$

Red clover necrotic mosaic virus, N-terminal 14 amino acids, $\mathrm{S} 109$

Reddy, J. D., S14, S87

Reddy, M. K., S35

Redinbaugh, M. G., S21, S84, S103, S134

Redlin, S. C., S65

Reed, S., S103

Reedy, C. J., S152

Rehmeyer, C. J., S87

Rehms, L., S35, S48

Rehner, S. A., S25

Reid, C. L., S22

Reinsel, M. D., S38

Reiser, J., S73

Reitz, S. R., S5

Remmenga, M., S63

Remote sensing, conductive polymer analyses, rapid disease detection, 419

Remphrey, W. R., S115

Rémus-Borel, W., S165

Ren, H.-Y., 1048

Renard, M., 578
Renick, L. J., S87

Resendiz, R., S77

Resistance

-apple to scab: resistance gene $V f$, breakdown, 364; resistance locus genes, 370

—barley to Fusarium head blight, deoxynivalenol relation, 1145

- Brassica napus to Leptosphaeria maculans, major genes, 578

- cassava to bacterial blight, quantitative trait loci and pathotypes, Africa, 1084

- corn to: Aspergillus ear rot and aflatoxin, 1107; fumonisin, Fusarium ear and kernel rot, 251

- gene function in pathogenicity and host specificity, S136

—Japanese pear to scab, induced resistance, 604

-lentil to Colletotrichum truncatum, races, 236

—melon to Fusarium oxysporum, race 1.2, 1331

-nematodes and aphids, underlying pathways, S112

- pea to disease, elicitor-coding gene, 651

- pepper to disease, major genes, systemic acquired resistance, 1376

-Phaseolus vulgaris to Beet curly top virus, Bct gene, 320

—poplar to leaf rust, genetic factors, 1358

-rice to blast: ethylene induction, 819; gene on chromosome 1, 515; Pi-ta gene, 296

—rice to Magnaporthe grisea, gene Pi7(t), 302

— soybean to Soybean mosaic virus, analyses, 687

- species concept, host pathogen interaction, S124

— systemic, induced on maize by Trichoderma, 147

-Thinopyrum ponticum to Tapesia yallundae, group 4 chromosome, 932

-Thinopyrum intermedium to Cereal yellow dwarf virus, 1102

- tomato to Tomato yellow leaf curl virus, Rep gene sequences, 490

-watermelon to Fusarium wilt, quantification, 832

-wheat to: leaf rust, quantitative trait locus, tagging, 1036; Septoria tritici blotch, partial, 497; Septoria tritici blotch, Stb4 gene, 1198; Stagonospora nodorum leaf blotch, mapping, trait loci, 1061

-woody plants, herbaceous plant model relevance, $\mathrm{S} 133$

Restrepo, S., S87

Reszka, E., S105

Revers, F., 289

Reviewers, acknowledgment, 4

Rhaiem, A., S87

Rhamnus alaternus, Pseudomonas savastanoi, histopathology, S102

Rheeder, J. P., S55

Rhizobium sp., biofilm formation, symbiotic genes, S32

-R. meliloti, plasmid-borne nor-nir genes, S15

Rhizoctonia spp.: on cereals, real-time PCR for identification, S77; on creeping bentgrass, fungicide programs, S58; potato, pathogenesisrelated proteins, $\mathrm{S} 111$

$-R$. circinata, varieties, specific primers, $\mathrm{S} 103$

$-R$. solani, on cowpea, seedling resistance, $\mathrm{S} 8$ polygalacturonase from, purification, S64; on potato and sugar beet, management systems, S109; on rice, in Arkansas, S107; soil, detection methods, 280; in soil, $R$. oryzae comparison, S82; on sugar beet, azoxystrobin and soil temperature, S51; on sugar beet, integrated management strategies, S5; suppression by plant residues, S49; on vegetables, Muscodor albus based fumigant, 1031

Rhizopus stolonifer, on sweetpotato, biofilms and antagonism, S32

Rhizosphere

-antimicrobial activities, metagenomic library, S59

—root exudates, transgenic roots, root cap gene expression, $\mathrm{S} 14$

Rhodes, L. H., S5

Rhododendron, Phytophthora ramorum, root infection, S60

Rice

-bacterial blight, resistance genes, developmental stages, S61

-bacterial leaf blight, phosphoglucose isomerase, 478

-blast: field resistance, minor and major genes, S58; flood effect on resistance, S96; gene on chromosome 1, linkage, 515; MST11 gene characterization, S53; partial resistance, ethylene induction, 819; Pi-ta gene, resistance in USA, 296; proteomic analysis, appressorium formation, S52; resistance gene cluster, S135; resistance genes, mapping, S23; secreted proteins from, S46; silicon induced, mechanism, S52; silicon-mediated, cytochemistry, S146; silicon-mediated resistance, S88; speciesspecific pathotypes, from Lolium, 454

- deletion mutant detection, spotted arrays, S90

—durable resistance, S135

- genome sequence, bacteria, S65

- genomics of host-parasite interactions, S47

-hoja blanca virus, transgenic and conventional resistance, $\mathrm{S} 135$

-Magnaporthe grisea, saturation insertional mutagenesis, S135

-panicle blight, detection with PCR, S92

- pest management, yield losses, tropical Asia, 672

—phytoalexins, blast resistance and silicon, 177

-resistance to fungi, allene oxide synthase gene, jasmonic acid, S70

—root and crown rot, in Iran, S92

- seedborne fungi, oils as seed treatment, S75

— sheath blight, molecular strategy, S96

-ubiquitination-related genes, fungal and bacterial response, $\mathrm{S} 46$

—Xanthomonas oryzae, rax genes, S135

Richards, K., S154

Richardson, J. M., S88

Richardson, P. A., S6, S14, S54, S55

Rick, S., S66

Riegel, D. G., 641

Riley, I. T., 1207, S85, S88

Riley, K. L., S16, S150

Riley, M., S39, S139

Riley, R. T., S120

Rimelspach, J. W., S159

Rimmer, S. R., S12

Rioux, D., S133, S164

Ripoll, D. R., S24, S58

Rippy, R. C., S88

Ristaino, J. B., S5, S35, S62, S129

Ritchie, D. F., 1376

Rivas-Davila, M., S37

Rivas-Valencia, P., S35

Rizzo, D., 1075

Robarge, W. P., S9

Robert, C., 712

Roberts, D. P., S46, S88

Roberts, P. D., S14, S105, S144

Robertson, C., S30, S92, S131

Robertson, N. L., S88

Robinson, T. L., S62

Robles, L., S85

Rodrigues, F. Á., 177, S88, S146

Rodriguez, C., S62

Roe, B., S115, S123

Rogers, J., S47, S53, S54, S88

Rogers, P. M., S88, S89, S161

Rogers, S., S112

Roh, J. H., S52

Rolland, D., 1305

Rollins, J. A., S88

Rolshausen, P. E., S89, S154, S155

Romeiro, R. S., S37, S63

Romero, A. M., 1376 
Romero, J., 69

Ronald, P. C., 302, S135

Rondonuwu, F., S61

Roose, M. L., S132

Roossinck, M. J., S112

Roper, M. C., S89

Rose, J. K. C., S24, S136

Rosecrance, R., S20

Rosellinia necatrix, hypovirulence, reovirus, 561

Rosenberg, M. S., 1013

Rosenzweig, N., S161

Rosskopf, E. N., S48, S113

Rossman, A., S27

Rosso, M. L., S34, S147

Roth, M. L., S60, S81

Rothrock, C. S., S7, S72, S89, S101, S147

Rott, M. E., S89

Rotylenchulus reniformis, on cotton, pathogen reactions, $\mathrm{S} 80$

Roumagnac, P., 138

Roumbos, C., S51

Rouse, D. I., S32

Roux, J., S74, S89

Rouxel, T., 578

Rowe, R., S78

Rowhani, A., S2, S61, S90, S91

Rowntree, J. M., S90

Roy, A., S10, S90

Roy, G., S90

Royer, T., S170

Rubaihayo, P. R., 743

Rubio, O. A., S161

Ruff, R., S42

Ruiz, C., S126

Ruiz-García, N., S35

Rupe, J., S7, S34, S144, S147

Rush, C. M., S67, S98, S111, S168, S169, S170, S171

Russin, J. S., S158

Russo, J. M., S44, S65, S130

Rutger, J. N., 296, S47

Ryba-White, M., S90

Rye, blight, salinity and cutting effect, S54

Ryu, C. (Okla.), S49

Ryu, C.-M. (Korea), 1259

Saad, A. T., S90, S102

Sabanadzovic, S., S2, S90, S91

Sabaratnam, S., S78, S91

Sacristán, S., 992

Safflower, Cercospora beticola alternate host, S57

Saftner, R. A., 44, S20

Saguaro cactus virus, coat protein, RNA silencing, S109

Sairam, R. V., S115

Sakaii, H., S135

Salcedo, E., S31

Salicylic acid, immunity receptor, identification, S55

Salm, H., 1315

Salmonella enterica, in phyllosphere, fitness, S128

Sampling, fractal-based, binary epidemics, 1215

Sams, C. E., S91

Samuels, G. J., S25, S138

Sanchez, J., S129

Sanchez, M. J., S91

Sánchez-Pina, M. A., 470

Sanders, F. H., S34, S94, S145

Sandhu, A., S91

Sandoval, C., 69

Sanger, M., 722

Sanità de Toppi, L., 203

Sanogo, S., 1004, S91

Santini, J. B., S162

Sardanelli, S., S28

Saremi, H., S91, S92

Sarova, J., S3

SARS coronavirus, vaccine, in edible plants, S85
Sasaki, A., 561

Sastre, P., 470

Satyanarayana, T., S92, S131

Saude, C., S92

Savard, M., 1145

Savary, S., 672, 883, S92, S110

Sawada, H., S104

Sawyer, T. L., S152

Sayler, R. J., S92, S94

Schaad, N. W., S43, S67, S85, S88

Schardl, C. L., 1178, S73, S87, S119

Schatz, B., S169

Scheef, E., S15

Schell, M. A., S62, S121

Schenck, S., S154

Scherer, M., S45

Scherm, H., 396, 1022, S21, S22, S75, S77, S124

Scheuerell, S. J., 1156, S127

Schiff, N. M., S59, S110

Schilder, A. M. C., S78, S91, S92, S161

Schilling, J. S., S93, S165

Schisler, D. A., 1267, S93, S96, S106, S115

Schizaphis graminum, luteovirus transmitted by, genetics, S12

Schlatter, A. R., 1198

Schlub, R. L., S97

Schmale, D. G., III, S93

Schmidt, C. S., 351

Schmidt, M. E., S158

Schmidt, O., 1207

Schmidt, R. A., 124

Schmidtling, R. C., 124

Schnabel, G., S93

Schneider, B. A., S17

Schneider, D. J., S121

Schneider, R. W., S13

Schneider, S. M., S11

Schneider, W. L., 868, S24, S93

Schnell, R. J., S85

Schnelle, M. A., S106

Schneller, Q. R., S163

Schnurbusch, T., 1036

Schoelz, J., S14, S110

Schroeder, B. K., S93

Schroeder, K. L., S82, S94

Schroeter, R., S48

Schulz, M. L., S89

Schulze, D. G., S103

Schwartz, H. F., 184, S33, S34, S56, S150

Schwartz, M. R., S31, S146

Schwegel, R., S94

Schwehr, R., S146

Schweitzer, P. A., S159

Sclerotinia spp.

- S. homoeocarpa: on bentgrass, nonhost and host resistance, S157; on bentgrass, oxalate oxidase activity and chemical treatment, S157; on bermudagrass, fungicides, S38; on creeping bentgrass, linkage maps and resistance, S14; hypovirulent isolates, mitovirus 3a, 917

$-S$. minor, on peanut, biocontrol with Coniothyrium minitans, $\mathrm{S} 82$

$-S$. sclerotiorum: on bean, resistance sources, $\mathrm{S} 157$; on canola, resistance evaluation technique, S157; diversity and recombination, S65; on dry bean, temperature and relative humidity effects, S39; oxalic acid produced by, guard cell regulation, S37; on Phaseolus coccineus, resistance, basis, S19; on potato, diversity, outcrossing, Washington, 737; sclerotial germination, model, 268; on soybean, regression modeling, 102

- S. rolfsii: compatibility groups and genetic variability, S92; sclerotium formation, genes, S101

Sconyers, L. E., S13, S147

Scorza, R., S24

Scott, R. E., Jr., S15

Sears, J. L., S62

Secor, G. A., S58, S156

Seebold, K. W., S94, S141, S147
Seed infection, corn, cowpea, tomato, and watermelon, bacterial distribution, S34

Seem, R. C., 438, 641, S33, S50, S53, S70, S76, S124

Segura, G., S50

Seifert, K. A., S163

Seijo, T. E., S64, S70, S94

Sembel, D. T., S61

Semenov, A. M., S94, S105

Semenov, A. V., S105

Semones, S., S109

Senior, M. L., 862

Seong, K., S122

Septoria spp., on woody perennials, phylogeny, S29

-S. musiva, on poplar, screening clones, S108

$-S$. tritici, on wheat: nitrogen effect, 712; resistance, mapping of Stb4 gene, 1198; triazole sensitivity, S20

Sequeira, L., 916

Sergeant, D., S112

Serratia marcescens, on cucurbits:

_ genome island and fimbrial proteins, S115

-vector, S170

Service, S., S5

Sether, D. M., S154, 1031

Setosphaeria turcica on maize, spatial diversity, eastern USA, 892

Seyb, A. M., S94

Seyran, E., S95

Seyran, M., S80

Sfakiotakis, E. M., 924, 1280

Shabala, S. N., S102

Shah, D. A., 33, S93, S95

Shaner, G., S72

Shao, J., S123

Sharma, K. D., S18, S132

Sharma, P., S135

Sharon, A., 632

Shelver, W. L., S57

Shen, Q. Q., 1145

Shen, Y., S135

Sheng, G., S70

Shepherd, C., S33, S95, S110

Sheppard, B. R., S79

Sherman, D. J., S93

Sherwood, J. E., S4

Sherwood, J. L., 333, S5, S74

Sherwood, T.A., 490

Shew, H. D., 780, S58, S100, S147, S169

Shi, A., S95

Shi, X., S95

Shier, W. T., S1

Shimoni, A., 94

Shintaku, M., S131

Shishkoff, N., S95

Shlevin, E., 132

Shoemaker, P. B., S63

Shollenberger, L. M., 76

Sh. Pekhtereva, E., S43, S67

Shugart, H., S6

Sidebottom, J. R., S167

Sikora, R. A., S51, S117

Silagyi, A. J., S147

Silicon, rice blast resistance mechanism, phyto-

alexin effect, cover photo, February, 177

Silva, H. V., S72

Silva, J., S104

Silva-Rojas, H. V., S21, S95

Sim, S. C., S23

Simard, M., S164

Simini, M., S96

Simko, I., S68

Simmons, C., S75, S114

Simmons, R. B., S26

Simpson, C. R., S93

Sims, J. J., S43

Singh, B., S103

Singh, H. M., 672

Singh, M. P., 819, S58, S96 
Singh, P. (Ark.), S47, S96, S107, S111

Singh, R., S169

Singh, R. P., 1368

Sinorhizobium meliloti, analysis, genomics platform, S93

Sirococcus conigenus, on red pine, seedling risk, S11

Sisto, A., 484

Sitton, J. W., S112

Sivasithamparam, K., S42, S60

Skaria, M., S80

Slaats, B., S149

Slininger, P. J., 1267, S93, S96, S106, S115

Slippers, B., S149

Smart, C. D., S50, S87

Smeenk, J., S129

Smilanick, J. L., S71

Smith, B. J., S147, S148, S167, S169

Smith, D., S12, S98

Smith, G. S., S96

Smith, J. (Mich.), S129

Smith, J. A. (UK), 268

Smith, K. P., 766

Smith, L. J., S97

Smith, R. F., S150

Smith, S., S45, S79

Smith, V. L., S164

Smith-Becker, J., S112

Smith-White, J. L., S7

Sniezko, R. A., 751

Snover-Clift, K. L., S97

Sobral, B., S124

Soderlund, C., S135

Soehner, S., S33, S66, S95, S110

Soilborne diseases, crop rotation and amendments, S125

Soilborne pathogens, solarization, moisture effect, 132

Soilborne wheat mosaic virus, postplanting environment effect, 527

Soil contamination, explosives in military sites, plant toxicity, S96

Soil microbiology, dematiaceous hypomycetes, conidial survival, S86

Soil solarization

-resistance induced, Trichoderma comparison, S59

-soilborne pathogens, thermal inactivation, moisture effect, 132

Soil texture, electrical conductivity measurements, S169

Sol, N. I., S57

Solanum spp. (see also Potato): late blight resistance, allelic mining, S91

$-S$. viarum, tobavirus from, characterization, S48

Solofoharivelo, M. C., S97

Somers, D. J., S22

Son, M. Y., S8

Sonchus yellow net virus, live cell imaging, 912

Song, J. Y., S45

Sorghum

- ergot: forecast system, S111; weather and severity in Texas, S171

- grain mold susceptibility, pericarp, plant color, and grain hardness association, S32

- gray leaf spot, cultivated in wild species, 743

- sorgoleone production, rotation and cultivar effect, S32

Soriano, I. R., 1207

Soto, M. J., S134

Soto-Aguilar, M. J., S17

Soto-Estrada, A., 52, S49, S97

Soufi, R., S141

Soybean

-Bean pod mottle virus effect on yield, S157

- Bean pod mottle virus and Alfalfa mosaic virus, Nebraska, S162

-Cercospora kikuchii, benzimidazol resistance, $\mathrm{S} 44$

-cyst nematode: extraction efficiency from soil,
S73; molecular response in cells, S42; sudden death syndrome, field microplots, S144; ubiquitin extension protein, S33

- disease resistance, screening method, S65

- frogeye leaf spot, strobilurin fungicides, S75

- fungicide seed treatment, S147

- green stem, Bean pod mottle virus cause, S158

- leaf blight, yield loss in Argentina, S158

-Phomopsis seed decay, resistance inheritance, S45

-Phytophthora root rot, resistance and tolerance, S29

- Phytophthora sp., unknown species in Illinois, S158

-Pythium damping-off and root rot, cultivar resistance, $\mathrm{S} 7$

- Quadris and Headline effect on epidemic and yield, S146

-Rhizoctonia root rot, fludioxonil and azoxystrobin for control, S12

—rust: aerobiological approach, S65; aerobiology and epidemiology risk, S44; airborne dispersion, Africa to South America to North America, S80; in Argentina, S44; myclobutanil for control, S79; proteins, resistance, S64; resistance genes, subtractive hybridization, S19

-Sclerotinia sclerotiorum, petiole inoculation, S161

-Sclerotinia stem rot: modeling, 102; plant population and row spacing effect, S159

- sudden death syndrome: Fusarium spp., mitochondrial DNA, S34; nematode and moisture, S112; screening technique, S146; sequence tags, S159

-Tobacco streak virus, temperature effect, S161

- viruses, seed transmission, RNA distribution, S40

Soybean dwarf virus, on soybean, in Wisconsin, $\mathrm{S} 84$

Soybean mosaic virus

-hypersensitivity, elicitor function, S38

-resistance, analyses, 687

- seed transmission, S99

- symptoms, transgenic enhancement, S61

- temperature effect on necrosis, S116

Sparks, D., S113

Spartina alterniflora, fungus pathogens, Louisiana marsh dieback, S13

Spear, R. N., S69

Speck, J., S1

Spence, R. M., S24

Sphaeropsis spp.

- S. pyriputrescens: on apple, in Washington, S53; on apple and pear, conidial germination factors, S54; mycelial and pycnidial growth, $\mathrm{S} 54$

$-S$. sapinea, on red pine seedlings, survey in Great Lakes region, S98

Spinach, downy mildew, resistance characterization, S44

Spinach curly top virus

-Curtovirus recombination, $\mathrm{S} 6$

-Curtovirus sp., new, Texas, 772

Spiroplasma spp.

-S. citri: plasmid, nucleotide sequence, S47; transposome mutagenesis, variants, S73

$-S$. kunkelii: genome, parasitism in insects and plants, S123; protein translocation pathways, S116

Spitsin, S., S85

Sporidesmium sclerotivorum, inoculum production medium, S160

Spotts, R. A., S13

Spruce-fir ecosystem, forest structure change, in North Carolina, S9

Squash, powdery mildew, genetic and chemical control, S165

Squash leaf curl virus

- coat protein mutants, analysis, S150

-Squash mild leaf curl virus comparison, molecular recombination and host range, $\mathrm{S} 11$

Sreedharan, A., S97, S169

Srinivasan, R., S111

Srivastava, R. K., 672

Staben, C., S87

Stacey, A. J., 209

Stack, J. P., S129

Stack, R. W., S33, S97, S98

Stagonospora nodorum, on wheat: host-selective toxin, sensitivity gene, 1056; population structure, New York, S7; resistance, S28; resistance mapping, quantitative trait loci, 1061

Stall, R. E., S6

Stamler, R. A., S98

Stanghellini, M. E., S27, S29, S76, S80, S98, S151, S153, S154

Stanosz, G. R., S11, S98, S108

Stanosz, J. C., S108

St-Arnaud, M., S166

Starner, V. R., S103, S150

Staskawicz, B. J., S135

Statistics

-applications in plant pathology, symposium, 999

-Bayesian analysis, symposium, 1027

—meta-analysis, symposium, 1013

-multivariate, overview for research, symposium, 1004

-nonparametric tests, disease associations, symposium, 1018

- parametrics and factorials, letter to editor, 33

- survival analysis, applications in epidemiology, symposium, 1022

Stavisky, J., S5

Steadman, J., S47, S65, S73, S124, S156

Steddom, K., S98, S168, S169

Steffenson, B. J., 858, S32

Stein, J. M., S67, S98, S168, S169

Steinlage, T. A., S99

Stenger, D. C., 772, S6, S32, S99, S106

Stensvand, A., S99

Steomer, K., S140

Stephenson, J., S37

Stephenson, M., S67, S157

Stevens, C., S32

Stevenson, K. L., S99, S147

Stevenson, T. W., S23

Stevenson, W. R., S88, S89, S161

Stewart, J. E., S99

St. Martin, S. K., S70

Stockinger, E., S123

Stockwell, V. O., 1228, 1286, S152

Stone, A., 868, S24, S93, S125

Stone, J. K., S152

Stotz, H. U., S19, S37

Strand, J. F., S11

Strausbaugh, C. A., S99

Strawberry

-anthracnose: fruit age effect, S70; genetic analyses, 446

—black root rot: biocontrol, S78; methyl bromide in Georgia, S10

-Clonostachys rosea on, Botrytis for sporulation suppression, S21

-fungicide and remote sensing, S66

-Fusarium wilt, biocontrol, S113

- gray mold: fungicides for, model, Ohio, S99; postharvest control with fungicide and yeast, S151

— phyllody, in Florida, S94

-root diseases, fungicides in Louisiana and Mississippi, S169

-Verticillium wilt, methyl bromide alternatives, S39

—viruses, North America, S104

Strem, M., S6

Streptomyces spp.: pathogenicity island transfer from pathogen to nonpathogen, S51; plant pathogenicity evolution, S123

$-S$. scabiei, on potato, esterase characterization, 
S26

-S. turgidiscabies, on potato, pathogenicity island and fas operon, S48

Strobel, G. A., S36, S117

Stromberg, E. L., S142

Strømeng, G. M., S99

Stuart, S., 1031

Stuber, C. W., 862

Stumpf, C. F., S100

Sturrock, R. N., 1235

Stylosanthes scabra, anthracnose, canopy size and high $\mathrm{CO}_{2}, 221$

$\mathrm{Su}, \mathrm{H} ., 396$

Su, Z., 1013

Subbarao, K. V., 396, S86

Sudarshana, M. R., S90, S100, S117

Sugar beet

-Pythium damping-off, suppression by bacteria, soil temperature effect, 351

-Rhizoctonia solani, seedling resistance, S74

-rhizomania, control strategies in UK, model, 209

—rhizomania and soil factors, yield effect, S98

Sugarcane, mosaic, virus, genetics, S36

Sukno, S., S100

Sulc, R. M., S5

Sullivan, M. J., S100, S147, S169

Sulzinski, M. A., S34

Summerell, B. A., S7, S61, S84

Summers, C., S31

Sumner, L. W., S20

Sun, G. Y., S100

Sun, P., S60

Sundin, G. W., S68, S86, S87, S116

Sung, S. S., S79

Sunter, G., 772, S6

Suppressive soil

-host genotype significance, microbial communities, S125

-indicators and mechanisms, soil properties, S125

Suslow, T., S127

Sutker, E. M., S59

Sutton, D., S98

Sutton, T. B., S63, S71, S82

Sutton, W., S16, S35, S48

Suzaki, K., 561

Suzuki, S., 244, 683

Swart, A., S88

Sweany, R., S23

Sweeney, L., 759

Sweeney, M., S66

Sweet potato leaf curl virus, detection, molecular hybridization, S105

Sweetpotato, viruses: interaction and assessment using PCR, S54; yield decline, S19

Swezey, S. L., S11

Swingle, P., S115

Symbiosis, ectomycorrhizal, transcriptome, S133

Sysak, R. W., S161

Szabo, L. J., 569, 632, S6, S79, S125

Taipe, J. A., S101

Taipe, M., S101

Taiwo, M. A., S101

Takach, J. E., S101

Takahashi, M., S104

Takehara, T., S101

Tally, A., S78

Tamba, H., 454

Tanaka, A., 454

Tanaka, M., 683

Tandeski, C. M., S107

Tang, J. Y., S160

Tang, X., S49, S121

Tang, Z., S57

Tanguy, X., 578

Tani, S., S48, S101

Tani, T., 454

Tanino, S., 813
Tao, Y., 402

Tapesia yallundae, on wheat, new resistance source, 932

Taylor, J. H., S101, S120

Taylor, R. J., S156

Taylor, S. E., S52, S53

Taylor, T. N., S119

Taylor, T. V., S102

Teaching

— case studies, S139

—field crop diseases, new resource, S97

-learning from research and experience, S139

- new technologies, S139

- plant pathology at Southern University, extension, S20

—-student diversity, challenges, S139

Tebaldi, N. D., S105

Tegg, R. S., S102

Tekauz, A., 432

Tello, J. C., 1094

Temple, T. N., 1286

Templeton, M. D., 1129

Temsah, M., S102

Teng, P. S., 672

Tentinger, K. D., S102

Tertuliano, M., S48

Teubig, P., S68

Thanassoulopoulos, C. C., 924, 1280

Thecaphora solani, on potato, molecular analysis, 875

Theobroma cacao

-Crinipellis perniciosa, genetic warfare, S51

-wounding, ethylene, methyl jasmonate, S6

Thies, J. A., S8, S102

Thinopyrum spp.

- T. intermedium, Cereal yellow dwarf virus resistance, basis, 1102

-T. ponticum, resistance source to Tapesia yallundae, 932

Thomas, A. C., S170

Thomas, P. E., S154

Thomas, S. L., S102

Thomashow, L. S., S8, S24, S67

Thompson, D. C., S17, S103, S150

Thompson, D. F., S31

Thompson, I. A., S103

Thompson, J. F., S103

Thompson, N., S6

Thomson, S., S15, S155

Thon, M. R., 1032

Thorne, J., S35

Thornton, C. R., 280

Thrall, P. H., S9, S126

Tian, D., S16, S40

Tian, M., S136, S156

Tian, T., S75

Tickes, B. R., S153

Tillage, root disease effect, wheat and barley in Idaho, S99

Tilletia spp., DNA extraction technique, S108

-T. indica: quantification in Texas fields, S98; teliospores, quantify with PCR, S169; teliospores, recovery in Texas fields, S168; teliospores in soil, PCR to quantify, S98; on wheat, environment effect in Mexico, S30

$-T$. tritici, on wheat, defense genes, S63

Timmer, L. W., 978, S3, S14, S56, S64, S72, S83

Tisserat, B., S5

Tjosvold, S. A., S103

Tobacco (see also Nicoiana spp.)

-bacterial wilt, mechanical transmission, S144

-black shank: fungicides, S144; race structure, $\mathrm{S} 147$; races $\mathrm{O}$ and $1, \mathrm{~S} 100$

-blue mold, resistance and fungicides in Virginia, S47

-harpin expression, hypersensitivity, 1048

Tobacco mild green mosaic virus, mixed infections and cross protection, 1337

Tobacco mosaic virus

—biomedical production in plants, S49 —rubisco activase silencing, attenuation, S20

Tobacco ringspot virus, on soybean, growth stages, $\mathrm{S} 83$

Tobiasz, M., S164

Toda, T., S103

Todd, J. W., S145, S168

Togminia minima, ascospore discharge, in California vineyards, S57

Tolin, S. A., 687

Tollefson, J., S10

Tomato

-Alfalfa mosaic virus, Am gene on chromosome 6,345

-bacterial wilt: calcium effect, S73; integrated management, S61; thymol as biofumigant, S46

-curly top viruses, beet leafhoppers, detection in California, S17

-damping-off in greenhouse, biocontrol, S164

-fruit rot: chemical fungicides, S158; fungicide sensitivity in Ohio, S37

-Fusarium wilt, suppression, growth media, 1094

—nematode and fungal/bacterial wilt, in Vietnam, S75

-Phytophthora infestans: antagonists, S63; new isolate, S96

—production systems, methyl bromide, S63

- programmed cell death gene, analysis, S109

-Ralstonia solanacearum, acibenzolar-S-methyl effect, S46

Tomato chlorosis virus, genome organization and sequence, $\mathrm{S} 111$

Tomato spotted wilt virus

$-\mathrm{N}$ protein monomers, nonelectrostatic forces, 759

-on tobacco: acibenzolar-S-methyl effect, S157; new symptom, S146; seedling treatments, S67

- tobacco thrips affected by, factors, S100

-vector: acquisition, thrips, 333; incompetence of Frankiniella tritici, midgut infection, S5; nontransmissible isolate, S74; suitability to host, 706

Tomato yellow leaf curl virus

- Rep gene sequences, engineered resistance, 490

-resistance, Thailand isolate, S19

Tonapi, V. A., 796

Tooley, P. W., 621, 983, S66, S95

Torto, T. A., S156

Tosa, Y., 454

Tospovirus sp., N gene, sequence comparison, $\mathrm{S} 1$

Trail, F., S122, S159, S161

Tranzschelia spp., microcyclic and macrocyclic forms, evolution, S79

$-T$. discolor, on peach, lesion development, analyses, 52

Traquair, J. A., S103

Tredway, L. P., S58, S103, S141, S167

Trees, Africa, bark wounds, pathogens, S89

Trent, M. A., S168

Trent, T. B., S170

Triana, M., S135

Trichoderma spp.: on oyster mushroom, Korea, $\mathrm{S} 81$; on sweet corn, nutrient uptake and nitrogen use effect, 1031; taxonomy, ecology, S138

-T. atroviride: biocontrol agent, enzyme association, S18; proteinase, characterization, S151

$-T$. hamatum, on strawberry, population and roots in soil, S57

-T. harzianum: growth in nonsterile soil, analysis, S79; maize seed treatment, pathogen interaction, 147; proliferation in soil, fluorescent protein and image analysis, 1383

-T. stromaticum, on Crinipellis perniciosa, phylogenetic analysis, S25

$-T$. virens: biocontrol strains, response elicitors, 171 ; protein in plant interaction, S26

Tricoli, D. M., S100

Trillas, M. I., 1094

Troitsky, A. V., S67

Tronsmo, A., S41 
Trouillas, F., S154, S155

Trout, T. J., S11

Truscott, J. E., 209

Trypanosomes, on coconut and oil palm, Latin America, S134

Tsai, C. W., S103

Tsai, H.-F., S132

Tsaltas, D. S., S103

Tse, J., 1075

Tsuchiya, K., S104

Tsuge, S., 478

Tsuno, K., 478

Tubajika, K. M., 1136

Tucker, S. L., S135

Tuell, J. K., S161

Turecheck, W. W., 1018, 1116, S104, S166

Turfgrass

—blight: fungicides, S66; protists, phylogeny, S22

-creeping bentgrass and tall fescue, foliar disease and yeast, $\mathrm{S} 3$

—disease management, Georgia, S82

—dollar spot: epidemics, spatial structure, S159; fungicide evaluation, S159

-management, disease diagnosis, Georgia, S146

— rapid blight, host range, S83

Turini, T., S37, S88

Turnip mosaic virus, on Arabidopsis, broadspectrum resistance, RNA silencing, 730

Tweddell, R., S164

Tylka, G. L., S73

Typhula spp., distribution in Wisconsin, Michigan, Minnesota, and Utah, S15

Tzanetakis, I., S66, S104

Uchida, J. Y., S104, S155

Uekusa, H., 730

Ueng, P. P., S105

Ugaki, M., 244, 683

Umemura, K., 813

Uncinula necator

-on grape, host barriers, 438

-mites for biocontrol, S70

- signaling and sporulation, S33

Unruh, J. B., S38

Uppalapati, S. R., S108, S152

Upper, D., S84

Urashima, A. S., 454

Uratsu, S., S100

Uromyces appendiculatus

-on bean: gene pools, S82; phenotypic and genotypic variation, S156

- species concept, host gene specialization, S124

Urs, R. R., S105

US crop grouping, international harmonization, S17

USDA Regulated Plant Pest List, pests of regulatory significance, $\mathrm{S} 11$

Ustilago spp.

-U. hordei, mating inhibitors, Ustilago and Tilletia spp. comparison, $\mathrm{S} 4$

$-U$. maydis: gene expression, $\mathrm{S} 33$; virulence genes, microarrays, $\mathrm{S} 122$

-U. scitaminea, races in Hawaii, S154

Usuki, F., 412

Utkhede, R. S., S155

Uyemoto, J. K., S20, S61, S91

Vaccine, plant-based, for HIV-1, S55

Vacha, J. L., S84

Valdovinos-Ponce, G., S132, S136

Valent, B., S47, S132, S136

Validov, S., S67

Vallad, G. E., S86

Vallejo, V., S158

Vallone, S., S44

Valverde, R. A., S105

Van, T. K., S87

van Bruggen, A. H. C., 396, S94, S105

Vancauwenberge, J. E., S106

Vandemark, G. J., S43 van de Mortel, M., S15, S105

van den Bosch, F., 789

van den Bulk, R. W., S105

van der Westhuizen, L., S55

van der Wolf, J. M., S105

van der Zouwen, P. S., S105

Van de Weg, W. E., 370

van Diepeningen, A. D., S94

van Elsas, J. D., 463

Vanetten, H. D., S109

Van Gundy, S. D., S75

Vanilla, Fusarium stem rot, in North Sulawesi, S61

van Loon, L. C., S108

van Overbeek, L. S., 463

van Pelt, J. A., S108

van Santen, E., S80

Van Wees, S., S122

van Winkle, D. H., S106

Vargas, J. M., Jr., S159

Vasanthakumar, A., 1164, 1172

Vasquez, S. J., S106

Vazquez, C., S64

Velasquez, L., S159

Vélez, H., S106

Venturia spp.

$-V$. inaequalis, on apple: biocontrol with Microsphaeropsis ochracea, timing, 1305; races, resistance locus, 370; resistance gene $V f$, founder effect, 364

$-V$. nashicola, on pear, induced resistance, multiple response, 604

Vera Cruz, C., S61, S135

Verbena canadensis, mixed virus infections, indexing, S24

Verdier, V., 1084

Verstappen, E. C. P., 613

Verticillium spp.

-V. dahliae: genetic variation, S86; on pistachio, rootstock effects, 388; on pistachio, stem symptoms, cover photo, April; on potato, distribution dynamics during season, $\mathrm{S} 32$

$-V$. lecanii, on citrus, protection against green mold, chitosan, 693

$-V$. longisporum, on Chinese cabbage, endophyte: for control, 412; cover photo, May

Vidaver, A. K., S73, S85, S88

Vidigal-Filho, P. S., S162

Vigier, B., 1145

Vigna unguiculata, fumonisin $\mathrm{B}_{1}$, in seed, S55

Vilchez, M., S43, S103, S108, S151

Villalobos, R., S52

Villanueva, E., S170

Villanueva, M. E., S67

Villareal, N., S135

Vincelli, P., S106

Vine, B. G., S155

Viret, O., 850

Virulence, evolution, plant-pathogen association, epidemiology and genetics, S126

Viruses

-luteovirus, aphid vectors, regulation, S134

-mixed infection, cytopathological structures, 111

-reovirus, hypovirulence of Rosellinia necatrix, 561

—rhabdovirus, host range, insect view, S134

-tospovirus, vector relations, disease spread, S134

Viveros, M., S17, S36

Vlot, A. C., S55

Vodak, M., S36

von Bodman, S. B., S41

von Broembsen, S. L., S79, S106

von Tiedemann, A., 584

Voss, K. A., S120

Vujanovic, V., S166

Wach, M., S106

Wada, Y., S49

Wakefield, L. M., S33
Wakulinsky, W., S3

Walcott, R., S30, S34, S59, S137, S145, S156

Waldrop, T. A., S118

Walker, A. M., S61

Walker, N. R., S107, S170

Walkinshaw, C. H., S107, S170

Wallen, C., S85

Wamishe, Y., S47, S96, S107

Wang, C.-H., 1031

Wang, D., S144

Wang, G.-L., S46, S135

Wang, J.-F., S61

Wang, J.-S., 1048

Wang, K.-H., S129

Wang, L., 515

Wang, M. L., S34

Wang, N., S63, S107

Wang, W. (Baoding, China), 1042

Wang, W. J. (Beijing, China), S29

Wang, X. (N.C.), S25, S43, S82, S100

Wang, X. (Wash.), S108

Wang, X.-J. (Va.), S107

Wang, X. K. (N.D.), S107

Wang, Y. Y., S43

Wang, Z., 296, S47

Wangdi, T., S108

Wanner, L. A., S108

Ward, T. J., S117

Warfield, C. Y., S7, S43, S167

Warnke, S., S14, S23

Warren, K. L., S93

Watercress, phytoplasma disease, Hawaii, S149

Watermelon

—Didymella bryoniae, strobilurin-resistant populations, fungicides, S147

-Fusarium oxysporum, resistance quantification, 832

Watling, M., 268

Watson, B. S., S20

Wayadande, A., S73, S170

Weather, site-specific estimation, spatial interpolation, S52

Wedge, D. E., S143, S148, S167, S169

Weeks, J. R., S13

Wegener, L., S66

Wegulo, S. N., S43, S103, S108

Wei, W., 244, 683

Wei, Z., S56

Weiland, J. E., S108

Weissinger, A. K., 82

Weller, D., S4, S8, S24, S67, S108

Wen, F., S14, S109

Weng, Z., S97, S109

Wentz, M., 858

Werner, N. A., S104, S166

West, C. P., S170

West, L., S109

Westphal, A., S112, S162

Weyman, P. D., S109

Wharton, P. S., S92, S109

Wheat

-barley yellow dwarf, insecticide treatment in Alabama, S9

- Barley yellow dwarf virus and Cereal yellow dwarf virus resistance, specific markers, S6

-biocontrol with agents in rhizosphere, S94

-crown rot, new Fusarium, S91

-emmer, Fusarium head blight susceptibility, molecular genetics, S33

-foliar diseases, assessment method comparison, S169

-Fusarium head blight: biocontrol with cholineutilizing strains, S93; forecasting methods, S72; rain splash dispersal, Ohio, 1342; resistance induced, S51; type 1 resistance, screening nurseries, $\mathrm{S} 98$

-Gibberella zeae: environment in Ohio, S82; genetic mapping, 520

- hydroponic growth, seed size effect, S170 
-leaf rust: disomic chromosome substitution series, S97; Lr26 resistance gene, variation, 632

-leaf rust and leaf tip necrosis, quantitative trait locus, tagging, 1036

-leaf rust and Septoria tritici blotch, nitrogen effect, 712

-Mycosphaerella graminicola: gene analysis, S2; genetic diversity in Kansas, S48; mitochondrial genome, natural selection, 261

- powdery mildew: distribution in China, geostatstics, S160; silicon effect, S165

-rust, resistance genes, S77

-Septoria tritici blotch: host resistance genes, mapping, S22; molecular mapping of Stb4 gene, 1198; partial resistance, 497

- Stagonospora nodorum, toxin sensitivity, gene mapping, 1056

- Stagonospora nodorum leaf blotch, quantitative trait loci, resistance mapping, 1061

- take-all: host growth model, 535

- tan spot and leaf rust, cultivar mixtures for management, 961

Wheat spindle streak mosaic virus

-postplanting environment effect, 527

-replication in protozoa, S163

Wheat streak mosaic virus

—nitrogen deficiency, remote detection, S168

-systematic replacement, S99

- on wheat, symptoms and assessment, S106

Wheeler, M. H., S18, S132

Whipps, J. M., 268

White pine (see Pine)

White, D. G., 251, 1107, S54, S120

White, G. J., S109

White, J. F., S165

Wiangjun, H., 1102

Wichmann, G., S110

Widdowson, J. P., 497

Wiggins, B. E., S110

Wilcox, W. F., 641, S50, S70, S110, S117

Wilkinson, H. T., S132

Willard, B., S123

Williams, C., S40

Williams, J. W., S32

Williams, P., 916

Williams, R., S66, S95, S110

Williamson, V. M., S62

Willie, K., S103

Willocquet, L., 672, 883, S92, S110

Wilson, A. D., 419, S110

Wilson, A. J., S110

Wilson, C. L., S32

Wilson, C. R., S18, S102, S110

Wilson, D. M., S48

Wilson, J. P., S48

Wilson, L. L., S76

Windels, C. E., S10, S90

Windom, G. E., S10, S150

Wingfield, B. D., S21, S119, S163

Wingfield, M. J., S21, S61, S74, S89, S119, S149, S163

Winston, E. M., S47, S111

Wintermantel, W. M., S111

Wise, K. A., S111

Wisler, G., 220, S111

Wisniewski, M. E., S46

Wolff, J. J., S121

Woloshuk, C. P., S120

Wolski, E. A., S111

Wong, F. P., S152

Woo, S. L., S139

Wood, D. A., S18

Wood decay, brown-rot fungi, oxalate regulation, S93

Wood, degradation, calcium effect in agar-block tests, S165

Woods, D., S12

Woodward, J. E., S50, S170
Workneh, F., S111, S170, S171

Wright, D. L., S145

Wright, L., S47

Wu, B. M., S86

Wu, J., S135

Wu, S.-C., S122

Wu, T., S91

Wu, Y-X., 584

Wyatt, J. E., S167

Wydra, K., 1084

Xanthomonas spp.: on coriander, Oregon, S85 strains identified by cytochrome $b 561, \mathrm{~S} 27$

$-X$. axonopodis: on cassava, quantitative trait loci, resistance markers, 1084; on onion, inoculum source in Colorado, S33; on onion, polyphasic characterization, 184; on onion, spatial and temporal analyses, 138; on soybean and pepper, programmed cell death, S15

-X. campestris: on bean, genetic diversity, coevolution, 593; on bean, races and differential lines, S73; cercosporin degradation by, S102; gene homologues, deletion mutagenesis, S14; PCR for detection, transplant seedling greenhouses, S23

$-X$. citri: on citrus, diagnosis, sampling methods, 61; on Key lime and grapefruit, hyperplasia and necrosis, S26

-X. oryzae: harpin gene, hypersensitivity and pathogen defense, 1048; on rice, phosphoglucose isomerase, pathogenicity, 478

Xia, Y., 296

Xiao, C. L., 446, S53, S54, S62, S112

Xie, Q.-G., S112

Xie, W., 766

Xing, L. J., S112, S162

Xiong, Z., S97, S109

Xu, J. R., S35, S53, S103, S122, S135

$\mathrm{Xu}, \mathrm{P} ., \mathrm{S} 112$

Xu, X.-M., S112

$\mathrm{Xu}$, Y. C., 402

Xylella fastidiosa

-on almond, leaf scorch association in California, S17

-biofilm-defective mutant, mutagenesis, 1031

-on citrus, grape, and periwinkle, strains, S60

-defined medium, glutamine, S44

-on grape: biofilm, antibiotic susceptibility, S66; on grape, calcium effect, S59; spatial pattern analysis, California, 1136; type I secretion, S87; Xanthomonas campestris comparison, signal interference, S75

-grape and oleander strains, differentiation, S41

- nursery occurrence in Maryland, S43

- on oak, phylogenetic analysis, S73

-on ornamentals, phylogenetic analyses, S152

- polygalacturonase mutant, characterization, S89

— sharpshooters, stylet activities, S6

-strain differentiation, PCR-based detection system, S3

— strain diversity, DNA markers, S61

-on sycamore, sharpshooter transmission, S59

Yadav, R., S135

Yakabe, L. E., S112

Yalpani, N., S74, S75, S114

Yamasaki, H., S20

Yan, F., S6

Yandoc, C. B., S113

Yánez, V. R., S28

Yang, C.-H., S95

Yang, R.-C., S113

Yang, W., S123

Yang, X. B., 102, 1004, S60, S74, S80, S83, S84, S146, S158, S160

Yang, Y., 490, S70, S92

Yang, Z. N., S132

Yao, C., S113
Yap, M.-N., S113, S162

Yasuda, N., S44

Yates, D., 221

Yates, I. E., S113

Ye, T. Z., S113

Ye, X. R., S132

Yeates, G. W., S128

Yeh, F. C., S113

Yelton, S., 912

Yergeau, E., S166

Yerkes, C., S113

Yin, B., S78

Yoder, K. S., S45

Yokomi, R. K., S131

Yonow, T., 805

Yoo, S. J., S45, S113

Yoon, J.-B., 1295

Yoshida, H., S78

Yoshida, K., 561

Yoshida, T., S104

Yoshimura, M. A., S155

You, I. S., S113

Young, C. S., 268

Ypema, H., S44, S45, S63, S94

Yu, F. Q., S12

Yu, S., S52, S81

Yu, X., 1235

Yuan, C., 1031

Yuen, J. M. F., S77

Yun, H. Y., S114

Yurgel, S., S93

Zack, J., S53

Zaitlin, D., 1178

Zamani, A., 1235

Zambino, P. J., S114

Zandstra, B., S156

Zdor, R. E., S31

Zee, F. T., S50, 1031

Zelenev, V. V., S94

Zeller, K. A., S48

Zeng, X., S60

Zettler, F. W., 220

Zeyen, R. J., S114

Zhang, C., S114

Zhang, D., S114

Zhang, H., S39, S170

Zhang, J., 842, S114, S115, S123

Zhang, Q., S115

Zhang, R., S100

Zhang, S., 1259, S62, S70, S93, S115

Zhang, X.-C., S115

Zhang, Y., S100, S115, S116

Zhao, B. L., 402

Zhao, X., S53

Zhao, Y., S116, S123, 912

Zhau, J., 261

Zheng, C., S116

Zheng, Y., S17

Zhong, Z., S150

Zhou, B., S46, S135

Zhou, F., S55

Zhou, L., S115

Zhou, S., S95

Zhou, X. G., 832, S116

Zhou, Y. C., S117

Zhu, D., 672

Zhu, M., 515

Zhu, Y. Y., S43

Zidack, N. K., 1272, S5, S36, S117

Ziemkiewicz, H. T., S93

Ziems, A. D., S83, S117, S162

Zietlow, O. T., S117

Zinsou, V., 1084

Zitomer, N. C., S117

Zitter, S. M., S117

Zivanovic, S., S91

Zwart, D. C., S118 